\title{
Some Alternatives to the Mixed Oxide Fuel Cycle
}

\author{
D. E. Deonigi \\ E. A. Eschbach \\ S. Goldsmith \\ P. J. Pankaskie \\ C. A. Rohrmann \\ R. D. Widrig
}

February 1977

Prepared for the

U.S. Nuclear Regulatory Commission 


\section{NOTICE}

This report was prepared as an account of work sponsored by the United States Government. Neither the United States nor the United States Nuclear Regulatory Commission, nor any of their employees, nor any of their contractors, subcontractors, or their employees, makes any warranty, express or implied, or assumes any legal liability or responsibility for the accuracy, completeness or usefulness of any information, apparatus, product or process disclosed, or represents that its use would not infringe privately owred rights.

PACIFIC NORTHWEST LABORATORY

operated by

BATTELLE

for the

ENERGY RESEARCH AND DEVELOPMENT ADMINISTRATION

Under Contract EY-76-C-06-1830 
by

D. E. Deonigi

E. A. Eschbach

S. Goldsmith

P. J. Pankaskie

C. A. Rohrmann

R. D. Widrig

February 1977

BATTELLE

Pacific Northwest Laboratories

Richland, Washington 99352 


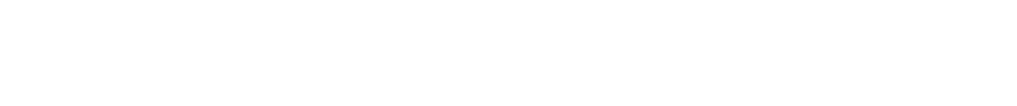

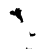

. 
While on initial examination each of the six concepts described in this report may have some potential for improving safeguards, none of the six appears to have any other major or compelling advantages over the mixed oxide (MOX) fuel cycle (1) And, in fact, compared to the MOX cycle, a11 but coprocessing appear to have major disadvantages, including severe cost penalties. Three of the concepts--tandem, extended burnup and rejuvenation--share the basic problems of the throwaway cycle (GESMO Alternative 6): without reprocessing, high-level waste volumes and costs are substantially increased, and overall uranium utilization decreases for three reasons. First, the parasitic fission products left in the fuel absorb neutrons in later irradiation steps reducing the overall neutronic efficiencies of these cycles. Second, discarded fuel still has sufficient fissile values to warrant recycle. Third, and perhaps most important, the plutonium needed for breeder startup will not be available; without the breeder, uranium utilization would drop by about a factor of sixty.

Two of the concepts--coprocessing and partial reprocessing--involve variations of the basic MOX fuel cycle's chemical reprocessing step to make plutonium diversion potentially more difficult. These concepts could be used with the MOX fuel cycle or in conjunction with the tandem, extended burnup and rejuvenation concepts to eliminate some of the problems with those cycles. But in so doing, the basic impetus for those cycles-el imination of reprocessing for safeguards purposes--no longer exists.

Of all the concepts considered, only coprocessing--and particularly the "master blend" version ${ }^{\mathrm{a}}$--appears to have sufficient promise to warrant

1 For purposes of this report, the mixed oxide fuel cycle is the base case, Alternative 3 (prompt uranium and plutonium recycle) fuel cycle described in GES:10, p. ES-4

a The master blend concept leaves some uranium with the plutonium process stream to obtain a desired plutonium enrichment level (probably in the $10 \%$ to $30 \%$ range) for a MOX "master blend" to be shipped to fuel fabricators. They would then blend in natural $\mathrm{UO}_{2}$ to reach the final enrichment level desired. The remaining uranium separated out in the reprocessing plant would be returned to the enrichment plant as in the MOX fuel cycle. Other master blend versions which mix natural uranium with the plutonium are discussed in Chapter IV, Section L of GESiMO. 
a more detailed study. The master blend concept could, on cursory study, make plutonium diversion more difficult with minimal impact on the reprocessing and MOX fuel fabrication operations.

In summary, each of the concepts has the following characteristics:

Tandem Cycle - The tandem cycle basically involves further irradiation of LWR spent fuel in a HWR, with fuel throwaway after the HWR step. In essence tandem is the equivalent of GESMO Alternative 6 (no uranium or plutonium recycle) with an additional irradiation cycle of perhaps 10,000 MWd/tonne built in. If HWRs similar to those currently available (e.g., the Canadian (ANDU) are used, the spent LWR fuel would have to be refabricated into rod bundles about 2-ft long. This would probably require a separate refabrication plant with the shielding of a reprocessing plant, and, possibly, the complexity of a MOX fuel fabrication plant. Alternatively, a HWR could probably be designed and developed to use spent fuel as is from LWRs. The refabrication step would not then be needed.

In either case, tandem shares many of the advantages and disadvantages of GESMO Alternative 6. The reprocessing, plutonium storage, MOX fuel fabrication and associated transportation steps in the MOX fuel cycle are eliminated. But a refabrication step may be substituted with associated irradiated fuel transportation. In tandem also the volume and costs of high-level waste disposal increase substantially. If a refabrication plant is required, equipment requiring major maintenance will probably have to be discarded because of the difficulties of remote maintenance, thus further increasing high-level waste quantities and disposal costs.

Fuel refabrication in the tandem cycle would also reduce fuel reliability (in the HWR for most tandem versions) and create quality assurance and accountability problems. These could, in turn, lead to fuel licensing problems and probably derating of existing HWR designs. But new HWRs would undoubtedly be built to minimize the economic penalties of derating (i.e., increase core size, but design other plant components for the "derated" power level). One advantage of the refabrication tandem cycle 
is that, by starting with existing HWR designs, the HWRs could start coming on line by perhaps the mid-1990s.

However, if a HWR is designed to utilize spent LWR fuel as is, the plants would not be coming on line before at least the year 2000 because of the time required for design, development, demonstration, and licensing of a new reactor concept. This concept would eliminate the costly refabrication step and improve fuel reliability. But it would still not be as good as that of fresh fuel, thus the HWR is still penalized.

Finally the capital costs of HWRs are at least 10\% higher than those of LWRs and uranium requirements are higher. The net result is a decided economic and environmental penalty for the tandem cycle, probably even by comparison to the throwaway cycle (Alternative 6).

Extended Burnup - Extended burnup of LWR fuels could conceivably be achieved by: (1) additional shuffling of fuel elements, rods and rod segments within the core to attain a higher average burnup; or (2) higher initial enrichments, or spike enrichments, used to drive the core to longer burnups.

Extending the burnup of LWR fuels affects the overall balance between fuel cost, neutron economy, fuel reliability, maintenance requirements and reactor plant availability. Utilities and fuel manufacturers are continually seeking to maximize burnups consistent with an overall optimization of these factors. Particular care must be exercised with schemes involving higher enriched or spiked fuels, for they can create power peaking problems which in turn lead to derating of the reactor. This would quickly obviate any benefits that might accrue from the extended burnup.

Finally, and perhaps most important, the residual plutonium in the spent fuel is still at a level which suggests the need for reprocessing-at least for breeder use if not for recycle and waste disposal purposes.

Fuel Rejuvenation - Fuel rejuvenation schemes do not appear to be 
technically feasible, with the possible exception of a total refabrication technique similar to that proposed for the tandem concept. But the costs and other problems of refabrication make that approach undesirable. Furthermore, any of these rejuvenation concepts would require high purity ${ }^{235} U$, which diminishes the potential value of restricting access to weapons material through discarding the plutonium produced.

Coprocessing - There are two basic approaches to coprocessing where plutonium is left with the uranium in the reprocessing plant product. One uses ${ }^{235} U$ to achieve the desired enrichment of the uranium-plutonium mix. The other, the "master blend" concept, combines some uranium with the plutonium stream to achieve a desired plutonium enrichment for the blend (probably in the $10 \%$ to $30 \%$ range). This master blend is then shipped to the MOX fuel fabrication plant where it is blended down to the desired final enrichment level with natural $\mathrm{UO}_{2}$.

Both approaches potentially increase the difficulty of diverting and obtaining weapon quantities of plutonium. And both approaches appear reasonably compatible with presently planned reprocessing plants although, depending upon the mixing scheme used, the master blend concept could cause resizing of the plutonium purification line. Both approaches would also require increasing the capacity of the $\mathrm{PuO}_{2}$ conversion facility.

Of the two concepts the master blend concept appears preferable to 235 $U$ enrichment: MOX plant throughputs are not increased; there is no need for high purity ${ }^{235} \mathrm{U}$, an attractive target for diversion; and there would be no blending loss.

However, a more detailed examination and demonstration of the master blend concept would be required to confirm whether it has any real advantages over the MOX fuel cycle. The preferred method of mixing and its ramifications on the separations process need more study and demonstration. For instance, the sintering characteristics and irradiation performance of the fuel need to be examined in more detail. Also the long-term implications of 
recycling spent uranium in the MOX fuel, including ${ }^{236} \mathrm{U}$ buildup, need careful study.

Partial Reprocessing - While there may be some safeguards advantages to leaving some gamma-intensive fission products with the plutonium through partial reprocessing, the additional costs of remote MOX fuel fabrication would probably eliminate any economic incentive for recycle if this concept were mandated.

Thorium - One of the principal reasons for considering the thorium cycle is to minimize plutonium production; however, the availability of weapons material and even plutonium is still a problem in the thorium cycle because the thorium must sti11 be enriched with ${ }^{235} U$. If lower enriched ${ }^{235} U$ is used to make it less attractive for diversion, substantial quantities of plutonium will be produced (e.g., if $20 \%{ }^{235} U$ is used, nearly one-third as much plutonium will be produced as that produced now in LWRs) because the neutronics of ${ }^{235} \mathrm{U}$-thorium cores especially favor plutonium production. Even $93 \%{ }^{235} \mathrm{U}$ would produce about $10 \mathrm{~kg}$ of plutonium annually in a 1000 MWe reactor. Furthermore, the ${ }^{233} \mathrm{U}$ produced is potential weapons material.

Another complicating factor is that using lower purity ${ }^{235} \mathrm{U}$ (e.g. $20 \%{ }^{235} \mathrm{U}$ ) requires increased enrichment in the initial core and also increases the amount of ${ }^{235} \mathrm{U}$ required for subsequent cores. The increased $235 \mathrm{U}$ requirement is aggravated by less ${ }^{233} \mathrm{U}$ being produced because of less thorium in the core and increased competition for neutrons by ${ }^{238} \mathrm{U}$.

Thus, a detailed analysis would be needed to define the "best" thorium cycle from a safeguards standpoint and to determine whether it has any advantage over the MOX cycle. An appropriate balance would need to be determined between ${ }^{235} U$ purity, plutonium production and throwaway, ${ }^{233} \mathrm{U}$ production, overall enrichment requirements and the subtle neutronic shifts involved.

However, none of these cycles appears economically viable, primarily because of two factors: the high separative work costs, particularly 
for initial cores; and the high cost of fabricating fuel in heavily shielded, remote facilities. And even if suitable incentives were provided to the industry to encourage thorium use, enrichment capacity and the establishment of an entire new fuel cycle would limit significant thorium use until at least the mid-1990s and probably well beyond the year 2000 . 


\section{CONTENTS}

SUMMARY AND CONCLUSIONS . . . . . . . . . . i i i

INTRODUCTION . . . . . . . . . . . . . . 1

CONCEPTS TO EXTEND EXPOSURE WITHOUT CHEMICAL REPROCESSING - 3

THE TANDEM CYCLE ............. . 5

Technical Feasibility of the Tandem Cycle . . . 7

Advantages of the Tandem Cycle . . . . . . 9

Disadvantages of the Tandem Cycle...... 10

Tandem Cycle: Conclusion. . . . . . . 16

EXTENDED BURNUP ............ 17

Technical Feasibility of Extended Burnup . . . . 19

Advantages of Extended Burnup....... . 19

Disadvantages of Extended Burnup . . . . . . 20

Extended Burnup: Conclusion . . . . . . 22

FUEL REJUVENATION . . . . . . . . . . . 23

Technical Feasibility of Fuel Rejuvenation. . . . 23

Advantages of Rejuvenation . . . . . . . 24

Disadvantages of Rejuvenation........ 24

Fuel Rejuvenation: Conclusion . . . . . . 25

CONCEPTS TO MODIFY REPROCESSING . . . . . . . 26

COPROCESSING . . . . . . . . . . 26

Technical Feasibility of Coprocessing . . . . . 28

Advantages of Coprocessing . . . . . . 28

Disadvantages of Coprocessing . . . . . . 28

Coprocessing: Conclusion........ 30

PARTIAL REPROCESSING .......... 31

Technical Feasibility of Partial Reprocessing. . . 31

Advantages of Partial Reprocessing . . . . . 31

Disadvantages of Partial Reprocessing. . . . 32

Partial Reprocessing: Conclusion. . . . . . 32 
THORIUM IN LWRS ........... . . 33

Thorium Background ......... . 33

Technical Feasibility of Thorium Cycles. . . . . 41

Advantages of Thorium Cycles ....... 41

Disadvantages of Thorium Cycles........ 42

Thorium Cycle: Conclusion ........ 45

BIBLIOGRAPHY ................. 46 
SOME ALTERNATIVES TO THE MIXED OXIDE FUEL CYCLE

\section{INTRODUCTION}

Many different concepts for securing further irradiation of otherwise spent light-water reactor fuel have been suggested at one time or another. Before the MOX fuel cycle was demonstrated, a long list of alternative fuel cycles was studied during the 1956 to 1967 period of time. However, few appeared sufficiently promising to justify even cursory engineering demonstration despite the reduced irradiation requirements that experts believed would prevail in a commercial nuclear enterprise. And only the MOX fuel cycle was demonstrated under the more severe conditions prevailing in light-water power reactors of today.

The purpose of this study is to briefly reexamine some of these: concepts in light of prevailing conditions to determine if any appear sufficiently promising to warrant a more detailed study. None of the concepts summarized in this report have been either fully studied or demonstrated. The MOX process was developed over many years of study, research, experimentation and demonstration; only in this way could the real benefits, problems and economics be identified. A11 too frequently, apparently promising industrial processes are discarded because, in implementation, some problem previously unrecognized or considered minor proves intractable. An overview, such as this study represents, seldom identifies all of these real problems.

Six of the potentially more promising fuel cycle concepts are considered here. These represent a fairly broad spectrum of the various ideas proposed in the past. While each has some interesting characteristics, none has any apparent compelling advantages over the mixed oxide fuel cycle and most appear to have some major disadvantages compared to the MOX cycle. The six concepts considered are:

1) Tandem cycle, where spent fuel from a LWR is further irradiated in a heavy water reactor (HWR) or other suitable reactor 
before being sent to high-level waste disposal. Neither uranium nor plutonium would be recycled.

2) Extended burnup, where the life of fuels in LWRs is increased before being sent to high-level waste disposal. Neither uranium nor plutonium would be recycled.

3) Fuel rejuvenation, where spent fuel from a LWR is reenriched for further irradiation without going through a reprocessing step.

4) Coprocessing, where the uranium and plutonium from spent fuel are maintained as one product from the reprocessing plant to increase the difficulty of diverting and obtaining weapon quantities of plutonium.

5) Partial reprocessing, where some gamma-emitting fission products are left with the plutonium coming from the reprocessing plant to make diversion more dangerous.

6) Thorium cycle, where ${ }^{238} U$ would no longer be used as the fertile fuel for LWRs and, therefore, plutonium would no longer be produced in large quantities.

Each of these concepts and some of their variations are described in some detai1; and the technical feasibility, advantages and disadvantages of implementing the concept are assessed in a cursory way. An extensive and time-consuming study would be necessary to quantify some of the judgments made in this report. We believe such a study would only serve to further elucidate and emphasize the magnitude of the issues presented here; the overall conclusions would not change. Ironically, further analys is seldom leads to increasing the number or magnitude of the advantages claimed for $z$ concept. For where we may be painfully aware of the shortcomings of an existing process, we also tend to be optimistic about solving those of a proposed process. 


\section{CONCEPTS TO EXTEND EXPOSURE WITHOUT CHEMICAL REPROCESSING}

The original impetus behind the tandem, extended burnup and fuel rejuvenation concepts was to extend fuel exposures rather than to eliminate reprocessing per se. In the late 1950s and early. 1960s demonstrated fuel exposures were low by today's standards, that is, 12 to 15,000 MWd/tonne rather than the $30,000 \mathrm{MWd} /$ tonne of today. It was anticipated that these concepts would allow further irradiation in the same or different reactor to thus achieve total exposures. not very different from the goal exposures of today. Considerable thought went into devising systems to maximize the utility of plutonium in thermal neutron reactors, particularly in view of the following characteristics:

1. The capture-to-fission ratio of ${ }^{239} \mathrm{Pu}$ (the major fissile plutonium species) is highly dependent upon the characteristics of the thermal neutron spectrum in which it is irradiated, and it is generally less favorable than that of ${ }^{235} \mathrm{U}$. Thus, gram for gram, the amount of energy generated by ${ }^{239} \mathrm{Pu}$ is less than that of ${ }^{235} \mathrm{U}$.

2. The composition of plutonium available for recycle consists of four isotopes in addition to ${ }^{239} \mathrm{Pu}$, each of which has significantly different characteristics. Plutonium-240 is a nonfissile species resulting from neutron capture in ${ }^{239} \mathrm{Pu}$. This happens in 30 to $40 \%$ of the instances in which ${ }^{239} \mathrm{Pu}$ absorbs neutrons. Plutonium-240, in turn, is not fissile but does have a large cross section to capture a thermal neutron and form ${ }^{241} \mathrm{Pu}$. The latter is a fissile species which forms ${ }^{242} \mathrm{Pu}$ when it absorbs a neutron without fissioning, which occurs in about 20 to $30 \%$ of the neutron absorptions. In addition, ${ }^{241} \mathrm{Pu}$ has a significantly short half-1ife--13 years--decaying to ${ }^{241} \mathrm{Am}$, a parasite in thermal neutron reactors. Plutonium-242 is also a parasite, capturing a neutron to form ${ }^{243}$ Am which does not fission readily with absorption of thermal neutrons. The isotopes, ${ }^{239} \mathrm{Pu},{ }^{240} \mathrm{Pu},{ }^{241} \mathrm{Pu},{ }^{242} \mathrm{Pu}$, are a chain extending from the same root. 
3. Plutonium-238 is also present in plutonium from thermal neutron reactors using slightly enriched uranium. It has a 90-year half-life, decaying by alpha emission. It is present principally from neutron capture in ${ }^{237} \mathrm{~Np}$ which, in turn, comes from ${ }^{236} \mathrm{U}$ which, in turn, is formed from neutron capture in $235 \mathrm{U}$. About $20 \%$ of thermal neutron absorptions do not lead to ${ }^{235} \mathrm{U}$ fission. Thus ${ }^{238} \mathrm{Pu}$ concentrations of a few percent can be present in plutonium recycle batches.

4. All of the plutonium isotopes, particularly ${ }^{239} \mathrm{Pu}$ and ${ }^{240} \mathrm{Pu}$, have larger thermal neutron absorption cross sections than those of $235 U$ and ${ }^{238} U$. Thus when substituting plutonium enrichment of uranium for ${ }^{235} U$ enrichment of uranium, one introduces an additional fertile species, ${ }^{240} \mathrm{Pu}$, and a significant parasite, ${ }^{242} \mathrm{Pu}$--and a major physical handling problem by virtue of the activity of ${ }^{238} \mathrm{Pu},{ }^{241} \mathrm{Pu}$, and, to a lesser extent, ${ }^{240} \mathrm{Pu}$. Moreover, the presence of these heavy therma 1 neutron absorbers in the reactor produces a neutron spectrum that further increases the capture-to-fission ratio of ${ }^{239} \mathrm{Pu}$; this lowers its value as a neutron and energy source.

5. A number of other factors, some very subtle, influence the optimum utilization of plutonium-uranium systems. For example, the long-term effects of ${ }^{236} U$ buildup and the comparative ease of plutonium separation (by chemical reprocessing) for enrichment purposes versus the cost of $235 U$ isotopic enrichment can significantly affect the overall economics of various cycles.

These considerations served as a stimulus to the world's nuclear community to identify and study a myriad of fuel concepts for various reactor types. However, the small gains and losses among these concepts weighed against the relative simplicity of the MOX fuel cycle suggest that mixed oxide fuels of one form or another should be the initial production form for plutonium utilization. Light-water reactors already generate nearly $50 \%$ of their energy by in situ fissioning of plutonium, 
i.e., plutonium that is intrinsically formed in the irradiation of $\mathrm{UO}_{2}$ fuels and thus already mixed in oxide form.

The following three approaches for potentially extending burnup and el iminating chemical reprocessing cover a wide spectrum of the ideas originally suggested.

\section{THE TANDEM FUEL CYCLE}

The tandem fuel cycle basically consists of reirradiating spent LWR fuel in HWRs without chemical reprocessing. ${ }^{a}$ In theory the spent LWR fuel, after about 30,000 MWd/tonne exposure, is good for at least another 10,000 MWd/tonne exposure in HWRs without removing the fission products (an exposure of 20 to $25,000 \mathrm{MWd} /$ tonne would be possible in a HWR if they were removed). At the $10,000 \mathrm{MWd} /$ tonne figure, one HWR could handle the output of about three LWRs. In practice, fuel reliability and fission product buildup problems could result in the need to alter the exposure conditions in order to optimize the overal1 tandem cycle. Graphite-moderated reactors could conceivably be used instead of HWRs; but the overall conclusions regarding the concept would not change if a graphite reactor were used.

A major concern for the tandem concept is the refabrication of spent LWR fuel into HWR fuel if presentl; designed HWRs (e.g., the Canadian (ANDU) are used. Several approaches are conceivable. Ideal1y, the LWR fuel element could be designed so that after irradiation it could be modified for insertion into a HWR without cutting into the fuel material. If the refabricated fuel is to go in a CANDU, the problem involves fabricating fuel elements about 2 feet long. The LWR fuel rods could be made up of 2-ft sections threaded together, each a finished, completely jacketed segment. The spent LWR fuel bundle would be taken apart and the individual 2-ft long segments inspected and rebundled for

\footnotetext{
a. Originally, the tandem fuel cycle concept did envision reprocessing to remove fission products before fabrication of HWR fuel.
} 
use in the HWR. In theory these operations could be accomplished in the LWR spent fuel storage basin. However, the feasibility of doing so routinely is another matter.

Alternatively, to minimize the number of welds and attendant fuel reliability problems in a LWR fuel bundle, zirconium or other inert metallic plugs could be inserted in the fuel rod every 2 feet. After discharge from the light water reactor, the rod is cut into $2-\mathrm{ft}$ lengths through the spacers and new end caps welded in place. In both concepts, an appropriately sized fission gas plenum arrangement would have to be provided in each 2-ft segment.

Several versions of the tandem cycle (with existing HWR designs) envision cutting directly into the spent LWR fuel. For instance: the cut sections could be reinserted into appropriately designed zirconium jackets, an end cap welded in place, and HWR fuel bundles made up using the rods as is; (2) the new rods could be swaged to improve heat transfer across the double wall cladding; (3) NaK or other soft metal intermediary could be used between the two zirconium clads to improve heat transfer; (4) the spent fuel could be vibrated out or otherwise removed from its original tubing, crushed and reinserted in new tubing by vibrational compaction (Vipac) techniques; or finally, (5) the spent fuel, after removal from its original tube, could be crushed, new pellets made and sintered, and loaded into new tubes for HWR irradiation. These options would require a refabrication plant that is heavily shielded--probably the equivalent of a reprocessing plant in this regard--with all refabrication operations performed remotely.

Another tandem cycle alternative would be to develop a heavy water or graphite-moderated reactor specifically designed to use spent LWR fuel as is, and thereby eliminate the need for refabrication. For example, a pot-type HWR similar to the West German reactor installed in Argentina (the 340 MWe Atucha plant) might be used.

In all cases, the spent fuel elements from HWRs would either go to a 
high-level waste final disposal site or be stored such that at some future time--perhaps 100 years from now--they could be mined for their residual fuel content (the stowaway cycle).

\section{Technical Feasibility of The Tandem Cycle}

While the tandem cycle is theoretically feasible, its feasibility has not been demonstrated. The ability to refabricate licensable HWR fuel from spent LWR fuel is a major concern if existing HWR designs are used. Even if segmented LWR fuel rods were used, it is not clear that rebundling operations could be successfully conducted on a routine basis. Removal and replacement of a small number of fuel rods have been done in specially designed fuel assemblies for the purpose of acquiring specific experimental data. In some cases, the fuel rod removal and replacement operations were done in the plant fuel storage basin. But these operations are difficult because they are remote and underwater. Extreme care must be taken to avoid damaging the fuel rod to the extent that fission products may be released into the working environment. Considering the risk of fuel rod damage and fission product release, it does not seem prudent to consider large-scale rebundling operations in existing spent fuel storage basins. Furthermore, it seems doubtful that the quality controls achievable in spent fuel storage basins would be acceptable for licensing considerations.

The alternatives to storage basin refabrication are to either construct special facilities at each plant site or to construct separate larger refabrication facilities to accommodate the output of multiple LWRs.

Another problem with any option involving segmented fuel is material accountability. Segments will vary significantly in burnup and residual enrichment. Some method must be developed to account for these differences and assure that the new HWR fuel bundle complies with enrichment specifications. 
Nor is it clear that cutting up LWR spent fuel to refabricate it into HWR fuel is technically feasible. It is doubtful that adding a new jacket to cut fuel segments can provide an acceptable HWR fuel. The heat transfer problem and the inability to incorporate adequate quality control and inspection techniques raise serious licensing questions for this fuel. Removal of the spent fuel from its LWR jacket and refabrication into new jackets could enable better homogenization of the fuel and probably provide a product more acceptable in terms of quality control and licensing. However, serious problems in handling and refabricating highly radioactive and chemically contaminated materials remain. For example, fission products are impurities and, as such, they will affect the sintering of the irradiated fuel material. They also could result in severe attack of the cladding, as evidenced by the pellet-clad-interaction failures currently being experienced.

Clearly the simplest and most feasible approach to achieve fuel integrity would be to use a second-stage reactor specifically designed to use spent LWR fuel as is. However, even in this "nonrefabrication" tandem cycle there may be a neutron exposure limit beyond which the risk of clad failure may be unacceptably high from licensing considerations. This concern may be partially mitigated through irradiation damage annealing of the fuel cladding. This same heat treatment may, however, release fission product gases to the extent that the internal pressure exceeds licensing requirements unless the fuel rod plenum can be adequately sized.

Furthermore, experimental evidence, although not yet fully substantiated, suggests that fission product gas release rates increase significantly at high (>20,000 MWd/tonne) burnups. ${ }^{2}$ Here again the combined effect of fill gas prepressurization and fission product gas release may result in internal fuel rod pressures unacceptably high unless the fuel rod plenum can be adequately sized.

2Personal communication, P. J. Pankaskie with C. R. Hann, C. E. Beyrs and ANS Working Committee. 
Advantages of the Tandem Cycle

The principal advantage of the tandem fuel cycle over the Mox fuel cycle is the elimination of reprocessing, plutonium storage and MoX fuel fabrication. Plutonium is never separated from the remainder of the spent fuel; hence opportunities for diversion are diminished. In effect this achieves many of the purported advantages of the throwaway cycle (GESMO Alternative 6$)^{3}$ with additional fuel burnup; although at least one, and possibly two, additional irradiated fuel transportation steps are required for tandem--LWR to refabrication plant (possibly) to HWR. These advantages should include an overall reduction in the volume of low- and intermediate-level wastes, particularly if no refabrication is required.

The tandem cycle would result in better utilization of uranium resources only if the throwaway cycle (Alternative 6) is the only other alternative. In that case tandem can increase the amount of energy generated by LWR fuels by about one-third (about 10,000 MWd/tonne). But tandem can never utilize uranium as efficiently as techniques which remove all or most of the fission products before further irradiation (i.e., in the MOX fuel cycle, coprocessing or partial reprocessing). For example, the spent LWR fuel could achieve about 20,000 to 25,000 MWd/tonne in a HWR if the parasitic fission products were removed first. Furthermore, the best fuel designs for LWRs or HWRs will probably have to be compromised to accommodate the design and operating characteristics of both types of reactors. Optimizing the overall cycle should at least partially mitigate these problems. Finally, the potential for increased uranium utilization for the "refabrication tandem" concept will be decreased somewhat by fuel losses if refabrication involves cutting into spent fuel rods.

The amount of separative work and $\mathrm{UO}_{2}$ fuel fabrication should decrease by about $25 \%$ over a throwaway cycle (Alternative 6 ). Lower

$\overline{3 \text { GESMO, pp. VIII-42 to } 46}$ 
electricity requirements for separative work, particularly if gaseous diffusion is assumed, may offset the added energy requirements for heavy water production. Note, however, that decreased separative work would result in any case from introducing HWRs into our nuclear system, not just because of the tandem cycle.

Disadvantages of the Tandem Cycle

There are a number of major disadvantages to the tandem cycle compared to the base case MOX fuel cycle assessed in GESMO. First, an entire new heavy water reactor industry must be established in the U. S., unless we turn to Canada or West Germany for HWRs of their design and thus further aggravate U. S. balance of payments problems. If the tandem cycle were adopted, some 100 to 150 HWRs (1000 MWe equivalent) would be needed by the year 2000 for equilibrium in the total nuclear system of 507 plants projected at that time in GESMO. ${ }^{4}$ By comparison, Canada, the only nation relying exclusively on HWRs, had only the equivalent of 13 HWRs (1000 MWe equivalent) operating or planned as of early 1976 with about 130 planned by the year 2000. ${ }^{5}$ Given the 225 LWRs (1000 MWe equivalent) currently installed or planned in the U. S. as of December 1976, about half the remaining reactors ordered for installation before 2000 would have to be HWRs to reach equilibrium.

Clearly it would be well beyond the year 2000 before the tandem cycle could be fully implemented, unless Canada were to use our spent LWR fuel-doubtful considering the fuel reliability problems involved. To design, demonstrate and license a HWR concept specifically tailored for the tandem cycle would probably take at least 10 to 15 years. Only then could utilities be expected to start placing orders in significant quantities. The tandem cycle HWRs would not be coming on 1 ine until at least 20 years after the initial decision was made to go tandem. However, the storage costs for spent LWR fuel are sma11, about $\$ 5 / \mathrm{kg}$ per year according to GESMO. 6

4 GESM0, p. S-17

5 Nuclear Engineering International, June 1976, p. 57.

${ }^{6}$ GESMO, p. S -52 
The alternative would be to 1 icense Canadian or West German HWRs in the U.S. The Canadian CANDU reactor is the best known. Preliminary analyses have indicated modifications would be required to permit licensing. ${ }^{7}$ Given the time required for necessary design changes, analyses, and licensing deliberations, it would probably be at least 5 years before utilities could begin placing orders. Thus, even CANDU-type HWRs would not be coming on line before the mid-1990s, and then only if manufacturers are willing to invest in HWR technology.

A second disadvantage is that additional heavy-water manufacturing facilities would also be required. These are energy-intensive operations, and their environmental impacts including doses to the public would have to be examined in detail.

Thirdly, if existing reactor designs are used, the HWRs and possibly the LWRs will probably have to be derated because of fuel quality and accountability problems. If segmented rods or rods with zirconium spacers were used in LWRs to simplify the refabrication process, the additional nonfuel space (i.e., for more end caps or spacers and for fission gas plenums) could reduce the efficiency of LWR operation. Severe flux perturbations may be a problem, and the overall fuel inventory would be reduced.

On the other hand, if present LWR fuel designs are retained (and in any case there would be a substantial inventory of presently designed LWR fuel built up before HWRs would become available), derating would be shifted probably entirely to the HWRs. Schemes involving cutting and adding another jacket to the spent LWR fuel result in major quality control uncertainties, heat transfer characteristics are uncertain, and an accurate fuel inventory may be difficult. Even if these double walled fuels could be licensed, the uncertainties would likely lead to a major derating.

Schemes that remove the fuel material from the old cladding and 7 "Study of the Developmental Status and Operational Features of Heavy
Water Reactors," prepared for EPRI by General Electric Company, San Jose, CA,
EPRI NP-365, Proj. 517-1, Final Report, February 1977. 
reinsert it in new cladding still have major quality assurance problems which would lead to derating. For example, fuel particle size and density control problems would limit the effectiveness of vibrational compaction (Vipac) techniques. Achieving uniform distribution of fissionable material is also a problem, and any zirconium chips left in the fuel can react with the oxide forming localized hot spots leading to fuel failures. Refabricating spent fuel into new pellets also has uncertainties: the crushing and grinding characteristics of irradiated $\mathrm{UO}_{2}$ fuel are unknown; fission products contaminate the fuel causing uncertain sintering characteristics and questionable pellet quality. Finally, quality assurance and inspection become increasingly difficult as the remote refabrication operation becomes more complex.

The possibility of derating would probably be at least partially mitigated in one of two ways. If existing HWR designs are used, they could be designed to minimize the economic penalties of derating. The . rest of the plant would be sized to match the expected derated power level. Alternatively, HWRs designed to accommodate LWR fuel as is should minimize fuel reliability and accountability problems. Derating should not be a mjaor problem in this nonrefabrication tandem cycle. The most significant problem appears to be the extent to which the fuel cladding can withstand the additional handling and burnup required. In addition, fissile material distribution in the LWR spent fuel element will be less than optimum and somewhat unknown. And it is questionable whether manufacturers' fuel warranties would be extended to the HWR irradiation cycle given the amount of fuel handling required.

Another disadvantage of the tandem cycle is that the burnup potential of the fuel in the HWR is about cut in half because of the parasitic fission products left in the fuel. Even sintering the irradiated fuel would not drive off the major neutron absorbing rare earth fission products such as samarium. And most of the gases released will rapidly build back up to their equilibrium value upon subsequent irradiation, resulting in little net decrease in neutron absorption. 
If the spent LWR fuel must be cut up to refabricate the HWR fuel, a costly refabrication plant will be required. This plant would combine the shielding and remote features of a reprocessing plant with much of the equipment and processes of the MOX fuel fabrication plant. Special precautions would have to be taken to contain the fission products released upon cutting the fuel and, if the fuel is resintered, additional releases will occur. Finally, it could be especially difficult to adequately decontaminate the fuel before shipment to the HWR plant.

The tandem cycle does not decrease the overall fissile plutonium concentration in the spent fuel; only the ${ }^{235} U$ concentration is decreased. Plutonium reaches near equilibrium level of about 5 grams fissile/kg heavy metal.

If the spent HWR fuel is sent to ultimate waste disposal, or even if a stowaway cycle is used (i.e., fuel buried but with the ability to mine the site at some distant time), the plutonium would not be available for breeder reactor initial cores. This in effect would reduce the energy potential of the fuel by a factor of about sixty. Of course the plutonium could be chemically separated from the spent HWR fuel, but this eliminates the principal advantage of the tandem cycle concept.

The total volume of high-level wastes would be at least threefourths that of the throwaway cycle which, in turn, is estimated in GESMO to be eight times that of the MOX fuel cycle. ${ }^{8}$ Tandem highlevel waste volumes could be even larger if refabrication plant equipment that breaks down has to be discarded rather than repaired remotely.

Another disadvantage is that the fuel reliability problems and the increased handling of irradiated fuel should increase occupational exposures, particularly at the HWR. The multiplicity of plant sites for both HWRs and LWRs (if storage basin refabrication occurs at the latter) could increase overall occupational exposure compared to the level at the relatively few reprocessing and MOX fuel fabrication plants 8 GESMO, p. VIII-44 
in the MOX fuel cycle. If fuel refabrication plants are needed, the exposures should be essentially equivalent to those of a reprocessing plant.

The tandem fuel cycle would cost substantially more than the MOX fuel cycle, and the added burnup potential would probably not be economically justified even if the MOX fuel cycle is not permitted. Assuming $10,000 \mathrm{MWd} /$ tonne burnup can be achieved with spent LWR fuel in a HWR, the spent fuel would have the equivalent value of natural $\mathrm{UO}_{2}$ to a HWR operation. This, of course, also assumes no penalty for such things as decreased fuel reliability and increased handling of irradiated fuel.

Natural $\mathrm{UO}_{2}$ fuel would cost about $\$ 175 / \mathrm{kg}$ using GESMO assumptions for $\mathrm{U}_{3} \mathrm{O}_{8}$ costs $(\$ 28 / 1 \mathrm{~b})$ and $\mathrm{UO}_{2}$ fuel fabrication $(\$ 95 / \mathrm{kg})$. $^{9}$ Actually fuel fabrication costs for CANDU HWRs should be somewhat higher as the shorter length (2 ft) means higher unit costs.

In addition, in GESMO it is estimated the spent fuel disposal costs would be $\$ 100 / \mathrm{kg} .^{10}$ With tandem the HWR operator still faces this cost, but the LWR operators do not. Therefore, about $\$ 75 / \mathrm{kg}$ is saved, making the total value of the fuel about $\$ 250 / \mathrm{kg}$. Thus the costs of refabrication must be considerably less than $\$ 250 / \mathrm{kg}-$-probably in the range of $\$ 200$ to $\$ 225 / \mathrm{kg}-$-to provide an economic incentive for tandem.

Clearly, in the nonrefabrication tandem cycle where the HWR is specifically designed to accommodate LWR spent fuel as is, fuel costs could look attractive even though a premium may have to be paid by the LWR operator for fuel destined for higher exposures:

However, if refabrication is required, the costs could rapidly offset any potential savings. For example, the least costly approach might be

\footnotetext{
${ }^{9}$ GESMO, p. S-52

$10_{\text {GESMO, p. } \times 1-30}$
} 
to use segmented LWR fuel rods. The extra welds and end fixtures would mean additional fabrication costs for the LWR fuel. The welding and end cap costs represent approximately $3 \%$ of total cost in present fuel assemblies. Thus, on a $12-\mathrm{ft}$ assembly a 15 to $20 \%$ increase in total fabrication costs could result. Still these fuel costs could look good if the fuel could be routinely refabricated at the LWR storage basin with a high degree of quality assurance and fuel reliability built in; but this is doubtful. More likely, the fuel would have to be shipped to a special plant for refabrication and the costs would increase substantially.

GESMO estimated that MOX fuel fabrication would cost about $\$ 200 / \mathrm{kg} .{ }^{11}$ The costs of major refabrication, where most of the MOX fuel fabrication steps are done in a hot cell-type facility with remote operation and maintenance, would be substantially higher--perhaps at least twice as high. In any case the $\$ 250 / \mathrm{kg}$ beginning value of the fuel would undoubtedly be more than offset.

The impact of power plant deratings is probably the overriding economic factor in these considerations though. As explained previously, this impact would be much greater for currently designed plants (e.g., CANDUs) than for plants designed specifically for tandem. LWR derating probably would be required also for those options involving segmented LWR fuels. Capital costs of these plants typically represent four times the cost per KW-hr that fuel expenses entai1. For example, a 10\% derating-and the deratings could be much greater--would have to be offset by a $40 \%$ savings in total fuel cycle costs which is inconceivable by these recycling techniques. Furthermore, the capital cost of the CANDU reactor is estimated to be at least $10 \%$ higher than LWRs, ${ }^{12,13}$ and costs to meet U. S. 1icensing

11 GESMO, p. S-58

12 Battelle-Columbus, "Study of Advanced Fission Power Reactor Development 13 for the United States," Vo1. 1, June 25, 1976.

"Study of the Development Status and Operational Features of Heavy Water Reactors" by M. J. McNelly and H. E. Williamson, Final Report to EPRI NP-365. 
requirements could increase this difference. So deratings of HWRs could have even greater impact on electricity generation costs.

Given the licensing uncertainties, the apparent unfavorable economics, and the major investment required to bring on a nuclear system, why should industry and utilities invest in the tandem cycle? Even if the LWR power generation costs were to increase dramatically, utilities would probably turn to fossil plants before tandem. The Federal Government would have to provide the incentives needed to el iminate the uncertainties and to gear an industry for the tandem cycle. And, even if suitable incentives were provided to implement a tandem cycle, some utilities, particularly the smaller ones, may not want to risk the potential cost penalties of installing an HWR in their system. Cooperative agreements may be required in addition to the necessary Federal incentives.

Tandem Cycle: Conclusion

Of the two versions of the tandem cycle, one utilizes HWRs of existing designs but requires refabrication of the LWR spent fuel, and the other utilizes specially designed HWRs to accommodate LWR fuel with no intermediate refabrication step. In either case, tandem shares many of the advantages and disadvantages of the throwaway cycle (GESMO Alternative 6).

The refabrication tandem cycle would encounter reduced fuel reliability (in the HWR for most tandem versions) and quality assurance and accountability problems. These could lead to fuel licensing problems and derating of existing HWR designs. But new HWRs would undoubtedly be built to minimize the economic penalties. However, the refabrication tandem cycle could be used with existing HWR designs, and the plants could start coming on line by perhaps the mid-1990s.

If a HWR is designed to utilize spent LWR fuel as is, the costiy 
fuel refabrication step is eliminated and fuel reliability should improve. But it would still not be as good as that of fresh fuel--the HWR is still penalized in this regard. Another problem with going to a new reactor concept is that the plants would probably not be coming on line until some time beyond the year 2000.

Also, regardless of whether fuel is refabricated, parasitic fission products are left in the HWR fuel. As a resuit, burnups of only about $10,000 \mathrm{MWd} /$ tonne are expected instead of the 20,000 to 25,000 MWd/tonne possible if the fission products were removed. Overall uranium utilization, while better than a throwaway cycle, would be substantially less than with plutonium recycle or cycles employing coprocessing or partial reprocessing.

Thus, given the unfavorable fuel performance, and the environmental, licensing and cost uncertainties, there appears to be no incentive at this time to develop the new HWR industry needed for the tandem cycle concept in the U. S.

\section{EXTENDED BURNUP}

There are four basic approaches to extending the burnup of fuel in LWRs to perhaps increase the attractiveness of a throwaway cycle. First, fuel can be shuffled within the core to reach a higher average exposure. ${ }^{a}$ This is already done to some extent in the three-or-four-cycle, core fuel management schemes used for PWRs and BWRs. However, more frequent shuffles could be used to achieve some marginal gains. Or individual fuel rods could be moved instead of entire fuel bundles. The rods could even be segmented so that segments could be rearranged to maximize axial exposures.

Second, the level of enrichment in the slightly enriched uranium cycle could be increased to drive the core to longer exposures. This is

${ }^{a}$ In effect, shuffling is done more or less continuously in CANDUs as fuel is moved in opposite directions in adjacent tubes. 
what has been happening during LWR commercial development. When commercial LWRs were first announced, goal exposures were about 17,000 to $18,000 \mathrm{MWd} /$ tonne. They are now about $30,000 \mathrm{MWd} /$ tonne, and vendors are evaluating the desirability of going higher.

Third, spike enrichments could be used to drive the core to longer exposures than would otherwise be achieved for a given level of initial enrichment. Endless combinations of spike enrichments are possible; most invoive inserting a highly enriched fuel element (the "spike") among a group of otherwise spent fuel rods. The spikes are distributed throughout the core, preferably in arrangements compatible with existing control rod systems. The spike system must produce more neutrons than it uses in order to provide excess neutrons to drive the otherwise spent rods to further exposure; it must also provide some conversion of fertile to fissile material in order to maintain appropriate lifetimes. The latter condition is critical to finding practical ways to achieve sufficient burnout of ${ }^{235} \mathrm{U}$ and plutonium to warrant the throwaway cycle.

Fourth, a seed blanket concept could be used wherein high fissile content fuel is placed in a zone in which it goes critical on its own. The zone is then surrounded by a blanket of high fertile content fuel. As the fissile core burns out, the bred fissile content of the blanket increases. The power generation of the reactor can then be shifted to the blanket fuel, or the blanket fuel can be moved into regions more appropriate for heat generation.

As in the tandem concept, the extended burnup concept envisions direct disposal of the spent fuel elements without chemical reprocessing or further recycle. A stowaway concept could be included whereby the buried fuel could be mined at some future time. 
Technical Feasibility of Extended Burnup

Some increased burnup appears technically feasible. But, as in tandem, plutonium levels will not change significantly. At ${ }^{238} U$ concentrations expected for these burnups, plutonium formation will about balance plutonium burnout. Furthermore, higher enrichment and spike and seed blanket schemes can lead to peaking problems; thus, LOCA constraints would limit the burnouts achievable.

Fuel reliability, as discussed under tandem, may also limit the burnup of the fuel. For example, the feasibility of routinely shuffiing individual fuel rods or rod segments in spent fuel storage basins is questionable. Increased fission gas generated will have to be accommodated. There may be some problems with fission product chemical attack at higher exposures, as evidenced by the stress corrosion cracking problems now being experienced. And data on very high burnup are not yet available to determine if there is a practical burnup limit beyond which irradiation damage to the fuel and cladding material increases the risk of failure to a level unacceptable for licensing.

\section{Advantages of Extended Burnup}

Like the tandem cycle, the principal reason for extending burnup of the LWR fuels is to increase uranium fuel utilization without plutonium recycle. However, extending burnup in existing reactors avoids the tandem cycle problem of introducing a new reactor system. A more detailed study would be required to determine how much additional burnup potentially could be achieved by these concepts. The peaking problem would probably be the 1 imiting condition, but it appears that perhaps 10 to $15 \%$ more burnup may be feasible. Perhaps 45,000 MWd/tonne could be reached under optimum conditions, or exposures approximating those for the tandem cycle.

Essentially the extended burnup concepts share many of the characteristics of a throwaway cycle (GESMO Alternative 6) with potentially better uranium utilization. Whether separative work requirements would also be 
reduced depends on how much benefit could be achieved from additional fuel shuffling; higher enrichment schemes will inevitably increase total separative work needs.

\section{Disadvantáges of Extended Burnup}

The extended burnup concepts have a number of disadvantages. Maintaining acceptable peak-to-average power ratios is probably the biggest problem with any extended burnup concept, particularly those involving higher enrichments. This appears to be the primary limitation on extending burnups, and could result in at least temporary derating of reactors to stay within LOCA 1 imits. To secure additional exposure in a nonbreeding nuclear reactor, one must increase the enrichment of the newest fuel and decrease the enrichment of the fuel ready for discharge so that the average is essentially unchanged. In large LWRs with relatively flat flux patterns, this necessarily leads to increasing differences between the peak-to-average-to-minimum rod powers.

Those concepts involving increased fuel shuffling would have least impact on peaking. They would also have least potential for extending burnup. Higher enrichment concepts, and particularly the spike concept, would have substantial difficulties meeting peak-to-average power criteria.

Spike fuels can burn out very rapidly (in a few months) because the only way to meet power limits with spike fuel is to restrict the amount of fissile material placed in the spike rod. There are some possible ways of circumventing this rapid burnout problem. One can design a spike element with some fertility present to breed fissile fuel and thereby prolong the allowable exposure. However, since the spike systems must generate excess neutrons, the fertility of the spike system must necessarily be substantially below the possible conversion ratio of the reactor core. In LWRs the average conversion ratio is about 0.7 ; thus the spike system should have a conversion ratio of less than 0.35 to be useful. With higher conversion ratios for the spikes, more spike rods are necessary. 
Thus, one soon finds the system uneconomic and incapable of handling significant amounts of otherwise spent LWR fuel. Other, more esoteric, approaches have been suggested in the past for obviating this spike burnout problem. But all appear to have major problems in implementation.

Seed blanket systems require control rods within each seed region. More rods will be required than in current LWRs, which reduces the average power level per rod. This could lead to the need for larger pressure vessels.

Spike and seed fuels may require highly enriched ${ }^{235} U$, which would be attractive for diversion. This would at least partially offset any potential benefits of not recycling the plutonium in the spent fuel.

Fuel reliability may decline because of additional handling (in schemes involving extensive fuel shuffling) and additional fission product interaction with the fuel and clad. Vendors would likely be reluctant to extend fuel warranties for fuel shuffling concepts involving individual rod movements.

If larger fission gas plenums are required in the fuel rods, less fuel can be inserted in present core designs and peaking problems will be further accentuated.

As described under the tandem cycle, concepts permitting individual rod movements or use of segmented rods will increase the design complexity and cost of the $\mathrm{UO}_{2}$ fuel element, although the added cost may be acceptable if 10 to $15 \%$ more burnup is possible. But it is questionable whether the rebundling operations required can be satisfactorily conducted on a routine basis in fuel storage basins.

Extensive fuel movements require more frequent reactor outages with possible reduction in reactor plant availability. The extent to 
which fuel can be moved will be determined by utilities' efforts to optimize refueling, maintenance, and system power generation requirements.

New core designs for LWRs and retrofitting are complicated by spike and seed systems which can effectively reduce the influence of control rods.

The plutonium content of the spent fuel will be about 6 to 7 grams fissile/kg heavy metal under any of the extended burnup schemes, essentially the same as in spent fuel at today's burnups. The problems of disposing of this plutonium have been described earlier.

The potential economic problems with any of the extended burnup concepts suggest caution in moving in this direction. First, if chemical reprocessing to at least remove parasitic fission products is permitted, it may prove more economic to reduce burnups as the cost of uranium and separative work increases. Extended burnup will only accentuate the inefficiency of leaving fission products in to soak up neutrons during the latter stages of the cycle. Furthermore, if higher enrichments are used, more burnable poison will be reqired early in the cycle; then extending burnup becomes even less efficient, and more uranium and separative work will be required.

The biggest economic issue though is probably derating. If peaking problems require derating reactors to achieve higher burnups, the cost could quickly offset any potential benefits.

Extended Burnup: Conclusion

Extending the burnup of LWR fuels affects the overall balance between fuel cost, neutron economy, fuel reliability, maintenance requirements and reactor plant availability. In particular, extended burnup concepts can lead to power peaking problems which may require derating the reactor. This would quickly override any benefits that might accrue from the 
extended burnup. In fact, extending burnup may be contrary to the longterm economic incentive to remove fission products more frequently for better neutron economy if uranium and enrichment costs increase disproportionate to reprocessing and MOX fuel fabrication costs.

\section{FUEL REJUVENATION}

Several ideas have been proposed for reenriching spent fuel for further LWR irradiations without chemical reprocessing. ${ }^{\text {a }}$ These include the use of cored fuel pellets in the initial fuel cycle; after irradiation, the rods would be opened and ${ }^{235} U$ inserted in the fuel core to provide sufficient enrichment for another fuel cycle. Another concept involves designing the fuel such that rings of fissile material could be installed around spent fuel rods, but no practical way to do this was ever developed. A chird conctpi wuld be to remove the spent fuel from its tubing in a refabrication plant (as in the tandem cycle), add ${ }^{235} \mathrm{U}$, and refabricate the fuel into new LWR fuel rods.

\section{Technical Feasibility of Fuel Rejuvenation}

Except for perhaps the total refabrication method, the feasibility of satisfactorily rejuvenating spent fuel by any of these methods is doubtful. Of the others, probably the most plausible technique would be to use cored pellets, for some experimental experience with cored fuel pellets has been encouraging. The core void would have to be a significant fraction of the fuel pellet. However, as the core void size increases, there is a tendency for spallation from the ID surface. This could cause serious difficulties in achieving a uniform and known distribution of enriched material throughout the length of the rejuvenated fuel rod. Furthermore, the ${ }^{235} \mathrm{U}$ should be distributed so as to compensate

\footnotetext{
There are other rejuvenation approaches, but they are beyond the scope of this study. For example, accelerators could be used as a source of neutrons to enrich spent fuel. But these neutrons are extremely expensive, and this approach would be clearly uneconomic. The spent fuel could also be reenriched by placing it as a blanket in fast breeder reactors or fusion reactors. When and if these plants become a reality, it may be worth considering such an approach in light of the overall economic, environmental and safeguards parameters of that time. None of these concepts eliminate plutonium.
} 
for the burnup (depletion) pattern resulting from the initial irradiation cycle.

Advantages of Rejuvenation

If it were feasible to rejuvenate spent fuel, the principal advantage would be to permit further burnup in a LWR without the need for chemical reprocessing and the other MOX fuel cycle steps. This has the advantages of the tandem cycle without the need to introduce a new reactor concept. It also has the advantages of the extended burnup concept without its peaking problems.

\section{Disadvantages of Rejuvenation}

Even if a technically feasible way were found to rejuvenate spent fuel without chemical reprocessing, there would be a number of problems. Total refabrication involves the same problems discussed under tandem: the need for a costly refabrication plant and refabrication process; quality and accountability problems in refabricating the fuel; higher occupational exposures in handling and recharging the fuel; fuel reliability problems in second stage irradiations; possible fuel licensing problems and possible reactor deratings from the fuel uncertainties.

However, compared to tandem, the refabrication cost of spent fuel for LWRs is further penalized. There is a "blending loss" in using highly enriched $235 \mathrm{U}$ to increase the total fissile enrichment to the $+3 \%$ level required. The combined enrichment of the spent fuel is about $1.4 \%$ fissile; thus to bring the average to $3 \%$, uranium with enrichments in excess of $3 \%$ must be mixed with the spent fuel. The process of enriching uranium in the $235 U$ isotope is quite expensive and becomes progressively more expensive as the enrichment level rises. As a result, highly enriched material mixed with low enrichment material results in a medium enriched product of lower average value than the sum of the two materials before mixing. This loss can be minimized by using the high enrichment 
material at an enrichment level only slightly above the desired final enrichment. However, while this process reduces the loss, it increases the quantity of material that must be remotely fabricated and would be extremely costly.

In the cored pellet concept the interface between the added $235_{\mathrm{U}}$ and the spent fuel could cause significant heat transfer problems (e.g., center melting) which would prevent licensing or require substantial reactor derating. The cored pellet concept also shares some of the drawbacks of the refabrication tandem process: expensive refabrication facilities; fuel reliability problems in working with frangible cladding material; questionable welding properties; and uncertain distribution of fissile material, leading to possible derating and licensing problems.

Like the tandem and extended burnup concepts, a 11 the rejuvenation concepts have the problem of leaving in parasitic fission products thus reducing neutron economies.

Like some of the extended burnup concepts, the rejuvenation concepts need highly enriched ${ }^{235} \mathrm{U}$, an attractive target for diversion.

\section{Fuel Rejuvenation: Conclusion}

With the possible exception of a total refabrication technique, none of the fuel rejuvenation schemes appear to be technically feasible. And, as described under tandem, the costs and other problems of refabrication make that approach undesirable. Furthermore, any of these rejuvenation concepts would require high purity ${ }^{235} U$, thus diminishing the potential value of restricting access to weapons material through discarding the plutonium produced. 


\section{CONCEPTS TO MODIFY REPROCESSING}

Two concepts have been proposed to modify the chemical reprocessing step to reduce opportunities for diverting plutonium. These are coprocessing, in which the plutonium and some or all of the uranium are processed together instead of separately, and partial reprocessing, in which some of the fission products are left with the plutonium to make diversion a more difficult and radioactively more dangerous task.

As discussed earlier, all concepts could benefit from chemical reprocessing to at least remove the parasitic fission products. Thus, while the following discussion of coprocessing and partial reprocessing emphasizes their use in the MOX fuel cycle, the concepts also could be used to partially mitigate some of the problems of the other fuel cycles discussed in this report.

\section{COPROCESSING}

In a conventional reprocessing plant the uranium and plutonium are coextracted in the initial solvent extraction step, partitioned, and the separate plutonium and uranium streams are each decontaminated in subsequent solvent extraction or ion exchange cycles. After purification, the uranyl nitrate is converted to $\mathrm{UF}_{6}$ and returned to the enrichment plant. The plutonium nitrate is converted to $\mathrm{PuO}_{2}$ for feed to the MOX fuel fabrication plant. With coprocessing, all or some of the uranium is left with the plutonium and the combined oxides used as feed to the MOX fuel fabrication plant.

Reenrichment of the coprocessed materiai for recycle into LWRs can be achieved by either a ${ }^{235} U$ enrichment or a "master blend" technique. With ${ }^{235} U$ enrichment the partitioning step in the reprocessing plant is eliminated. All uranium and plutonium is sent through a common purification cycle and then converted to a mixed oxide. Uranium-235 is then added to enrich the mixed oxide to the level required for MOX fuel fabrication. The $235 U$ purity will determine the characteristics of the remaining fuel cycle 
steps. If very highly enriched ${ }^{235} U$ is used (93\% or even $99 \%$ ), the quantity of MOX fuel fabricated will approach that in the GESMO MOX fuel cycle. At the other end of the spectrum, the ${ }^{235} U$ concentration could be adjusted such that the coprocessed material is blended with all the fuel material for reactor reloads ${ }^{a}$, and all fuel would be fabricated in the MOX fuel fabrication plant.

The other alternative is to leave or mix only enough uranium with the plutonium to achieve a plutonium-enriched "master blend" (e.g., 10 to 30\% Pu) as feed to the MOX fuel fabrication plant. At the MOX plant the master blend is mixed with natural $\mathrm{UO}_{2}$ to achieve the final enrichment level desired, and the same quantity of MOX fuel would be fabricated as in the GESMO MOX fuel cycle.

There are two approaches to achieving this master blend. An appropriate amount of uranium could be left with the plutonium in the partitioning step of the reprocessing plant, and the combined stream would then be purified and converted to the oxide. The remaining uranium would be processed as in the conventional reprocessing cycle.

Alternatively, the mixing could be done after the plutonium and uranium purification steps. Some uranyl nitrate would be mixed with the plutonium nitrate before conversion to oxide. This process is described in Chapter IV, Section L of GESMO (although fresh uranium is suggested as the blending material, a possible alternative to the approach described above). A further variation is also described, that is, mechanically blending $\mathrm{PuO}_{2}$ and fresh $\mathrm{UO}_{2}$ at the end of the oxide conversion process.

A separate approach would be to use the coprocessed uranium and plutonium without further enrichment in HWRs, the concept originally conceived for the tandem cycle.

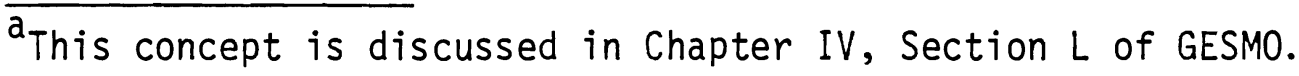


Technical Feasibility of Coprocessing

There appear to be no major technical problems that preclude any of the coprocessing options described, although none have been fully demonstrated.

\section{Advantages of Coprocessing}

The basic advantage of coprocessing is that it increases the difficulty of diverting significant quantities of plutonium. More total material would have to be acquired to obtain enough plutonium for a weapon, and a chemical separation step would be required to obtain reasonably pure plutonium. In the ${ }^{235} U$ enrichment concept, plutonium is never separated from uranium in the fuel cycle and, in fact, remains less than $1 \%$ of the fuel being processed. Plutonium is also never separated in the master blend scheme which removes only part of the uranium in the partitioning step. However, the other master blend options do involve a complete separation of plutonium at least through the purification cycles.

The ${ }^{235} \mathrm{U}$-enriched coprocessing concept also has the potential advantage of simplifying chemical reprocessing. The partitioning, plutonium purification and $\mathrm{UF}_{6}$ conversion steps would not be required. But this would be at least partially offset by the substantially increased (more than 100 times) oxide conversion requirement.

\section{Disadvantages of Coprocessing}

The potential problems of coprocessing differ depending on whether the ${ }^{235} \mathrm{U}$ enrichment or master blend concept is used. If $\frac{235 \mathrm{U} \text { enrichment }}{235}$ is used, a tradeoff exists between using high or low purity ${ }^{235} U$. With low purity ${ }^{235} \mathrm{U}$, the quantity of MOX fuel which must be fabricated, and thus the cost, increases substantially (e.g., by a factor of nearly five if $20 \%{ }^{235} U$ is used or nearly 16 if $4 \%{ }^{235} U$ is used). On the other hand, high purity $235 U$ is attractive weapons material and separative work costs increase. 
In fact, the "blending losses" described under fuel rejuvenation will occur with any coprocessing scheme that uses ${ }^{235} U$ enrichment. The loss is greatest if highly enriched ${ }^{235} U$ is used because of the disproportionately high amount, and therefore cost, of separative work required to obtain the high purity material. The loss would be progressively less as the ${ }^{235_{U}}$ concentration approaches the desired final enrichment level.

Sti11 the most significant issue with ${ }^{235} U$ enriched coprocessed material is probably the additional MOX fuel which must be fabricated. Using GESMO assumptions of $\$ 200 / \mathrm{kg}$ for MOX fuel fabrication versus $\$ 95 / \mathrm{kg}$ for $\mathrm{UO}_{2}$ fuel fabrication, any additional MOX fuel is penalized $\$ 105 / \mathrm{kg}$ compared to the GESMO MOX cycle. And plutonium-bearing wastes will also be increased. Finally, the capacity of the $\mathrm{PuO}_{2}$ conversion facility wil1 have to be increased to accommodate a 11 the coprocessed uranium and plutonium material -- a capacity increase of more than 100 times.

If the master blend concept is used, the MOX plant throughput will be the same as the GESMO MOX cycle. And there will be no blending loss as there is with ${ }^{235} U$ enrichment.

But there will be some impacts at the reprocessing facilities. These will vary depending on where the uranium-plutonium blending occurs. For example, if some uranium is left with the plutonium in the partitioning step, the plutonium purification 1 ine will have to be resized to handle the increased volume of material. Also, it will probably not be possible to control the exact concentration of the mix; a variation of a few percent in the plutonium concentration can be expected.

If the uranium and plutonium are mixed after the purification steps, essentially pure plutonium will be present in the process and could be a target for diversion.

Finally, compared to the GESMO MOX cycle, the $\mathrm{PuO}_{2}$ conversion facility capacity would have to be substantially expanded. But this expansion would 
be at least 10 to 30 times less than if ${ }^{235} \mathrm{U}$ enrichment were used. And no expansion would be needed if $\mathrm{UO}_{2}$ and $\mathrm{PuO}_{2}$ powders were blended mechanically after the oxide conversion step, as suggested in GESMO Chapter IV, Section L.

Both the ${ }^{235} \mathrm{U}$ enrichment and master blend concepts share two problems. First, compared to fuel cycles not needing reprocessing, the coprocessed material may still be attractive to terrorists. A relatively simple chemical separation step is all that is required to separate out the plutonium. However, thịs takes time and much more material must be diverted. Second, MOX fuel fabricators working with already blended materials inherently relinquish some quality control over powder characteristics to the reprocessor. This could create some problems for the fuel fabricators in their fuel warranties.

\section{Coprocessing: Conclusion}

The diversion of weapon quantities of plutonium is potentially more difficult with coprocessing. It also appears that both the master blend and the ${ }^{235} U$ enriched coprocessing concepts can be adapted to conventional chemical reprocessing plants, although $\mathrm{PuO}_{2}$ conversion facilities will probably have to be substantially expanded.

Of the two concepts the master blend appears preferable to ${ }^{235_{\mathrm{U}}}$ enrichment: MOX plant throughputs are not increased; there is no need for high purity ${ }^{235} U$, an attractive target for diversion; and there would be no blending loss.

However, a detailed examination and demonstration of the master blend concept would be required to confirm any real advantages over the MOX fuel cycle. This study must include determining the best method to obtain blending and whether there is any advantage in using fresh rather than spent uranium. The long-term implications of recycle of spent uranium, including ${ }^{236} U$ buildup, need to be carefully examined also. Finally, such things as the sintering characteristics and irradiation performance of the fuel need to be determined. 
PARTIAL REPROCESSING

In partial reprocessing, plutonium is separated from uranium, but only the uranium has the fission products fully removed. While most of the fission products could be removed from the plutonium, the gamma activity of the remaining products would still be so high that the dangers of diverting plutonium would be magnified. Alternatively, the plutonium could be fully purified and some selected high-gamma fission products mixed back in before it left the reprocessing plant (one of the concepts suggested for "spiking" fuels).

Technical Feasibility of Partial Reprocessing

Partial reprocessing appears technically feasible in currently designed chemical reprocessing plants. Although it has not been routinely demonstrated, it is likely that plutonium retrieved immediately after the partition cycle would be sufficiently contaminated with gamma-emitting fission products to meet partial reprocessing objectives. The MOX fuel fabrication plants would have to be redesigned to incorporate the necessary additional shielding and remote fabrication features to accommodate the higher dose rates.

\section{Advantages of Partial Reprocessing}

The principal advantage of partial reprocessing is the potentially increased difficulties and risk of plutonium diversion. Also detection techniques may be enhanced because of the high gamma activity of the plutonium.

Partial reprocessing, unlike coprocessing, also retains the inherent advantage of separating the plutonium from the depleted uranium. Until natural uranium costs more than about $\$ 50$ /pound, the ${ }^{235} U$ contained in it represents one of our least expensive energy sources. An earlier study ${ }^{14}$ $\overline{14}$ E. A. Eschbach and M. F. Kanninen, "Uranium Price Schedules and Bred Fuel Value," HW 72219, December 1964. 
showed that the value of plutonium is 20 to $30 \%$ greater when plutonium is burned with uranium containing ${ }^{235} \mathrm{U}$ rather than with essentially pure ${ }^{238} \mathrm{U}$. Thus, if plutonium is not mixed with fresh uranium containing ${ }^{235} U$, this advantage is lost. However, this may not be a major issue at the fuel exposures anticipated.

\section{Disadvantages of Partial Reprocessing}

The main disadvantage of partial reprocessing is the additional shielding and the costly remote operations required at the MOX fuel fabrication plant. A refabrication plant similar to that for tandem would be required. The added capital cost and remote operation and maintenance would likely increase MOX fuel fabrication costs to the point that plutonium recycle would no longer be economically justified.

A similar problem would occur at the $\mathrm{PuO}_{2}$ conversion facility. This would have to be heavily shielded and the operations performed fully remotely.

Compared to either coprocessing or the GESMO MOX cycle, occupational exposures (particularly at the LWRs) may increase slightly; and because damaged MOX plant equipment would have to be discarded, the quantity of high-level wastes would also be increased. Contact maintenance would probably not be possible on all equipment, even with decontamination facilities built in, and remote maintenance is difficult and costly. While the MOX plant under the standard GESMO cycle would also have contact maintenance problems, they would be substantially less than those encountered using partially reprocessed material.

The problem of leaving some parasitic fission products in the fuel to absorb neutrons in subsequent cycles should be minor compared to those cycles that use no chemical reprocessing.

\section{Partial Reprocessing: Conclusion}

While there may be some safeguards advantages to making the plutonium radioactively more dangerous through partial reprocessing, the additional costs of remote MOX fuel fabrication would probably eliminate any economic incentive for recycle using this material. 


\section{THORIUM IN LWRS}

To start and maintain a thorium- ${ }^{233} U$ cycle in LWRs, either plutonium or ${ }^{235} \mathrm{U}$ must be added as enrichment. This section examines thorium cycles using ${ }^{235} U$ in ${ }^{238} U$ at purities ranging from $20 \%$ to $90+\%$. Plutonium as enrichment is not considered, for the focus here is to examine cycles that do not involve large quantities of plutonium.

\section{Thorium Backaround}

Lacking a fissile species in nature, thorium must be enriched with either ${ }^{235} U$ or plutonium. With neutron absorption, thorium forms ${ }^{233} U$ which, like ${ }^{235} \mathrm{U}$, is relatively easily fissioned. Thus the classical 233 -thorium cycle involves recycling ${ }^{233} \mathrm{U}$ back into fresh thorium. Ideally, enough ${ }^{233} U$ would be formed so as not to require additional fissile material from the outside $\left({ }^{235} \mathrm{U}\right.$ or $\left.\mathrm{Pu}\right)$. Upon casual inspection, the initial enriching of thorium appears well worth the special fissile investment because (as Table 1 shows) in thermal neutron reactors, ${ }^{233} U$ yields 2.25 neutrons per neutron absorption while ${ }^{235} U$ and plutonium yield only 2. Thus it appears that as much ${ }^{233} \mathrm{U}$ could be bred as is consumed. In addition, the neutron yield of ${ }^{233} U$ is relatively independent of the hardness and effective neutron temperature of the thermal neutron flux in which it is irradiated.

Based on these characteristics, the thorium cycle would appear superior to plutonium recycle and even ${ }^{235} \mathrm{U}$ enrichment in LWRs, which have relatively hard neutron spectrums. But this is not the case. Supplemental enrichment is required, the reasons for which require further examination.

Figure 1 shows the thorium and uranium systems in a parallel format and shows some striking similarities and contrasts. For instance, upon neutron capture, both ${ }^{238} \mathrm{U}$ and thorium form fissile material-- ${ }^{239} \mathrm{Pu}$ from ${ }^{238} \mathrm{U}$, and ${ }^{233} \mathrm{U}$ from ${ }^{232} \mathrm{Th}$. Uranium-233 and ${ }^{239} \mathrm{Pu}$ fission in most cases upon neutron absorption, or capture neutrons in a minority of instances to form a fertile species, ${ }^{234} U$ and ${ }^{240} \mathrm{Pu}$ respectively. These fertile isotopes, in turn, form ${ }^{235} \mathrm{U}$ and ${ }^{241} \mathrm{Pu}$ upon neutron capture. Both fission 


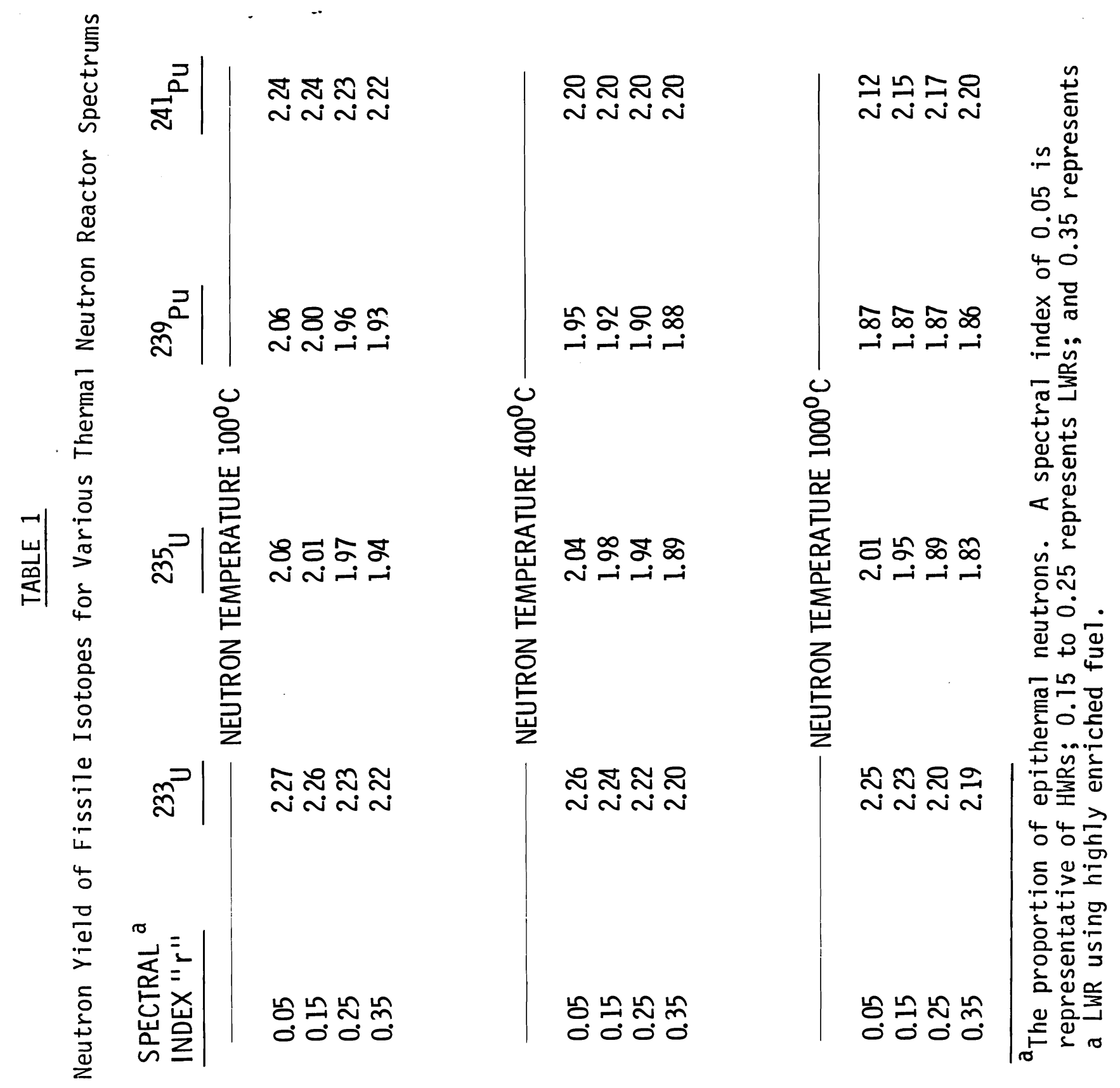




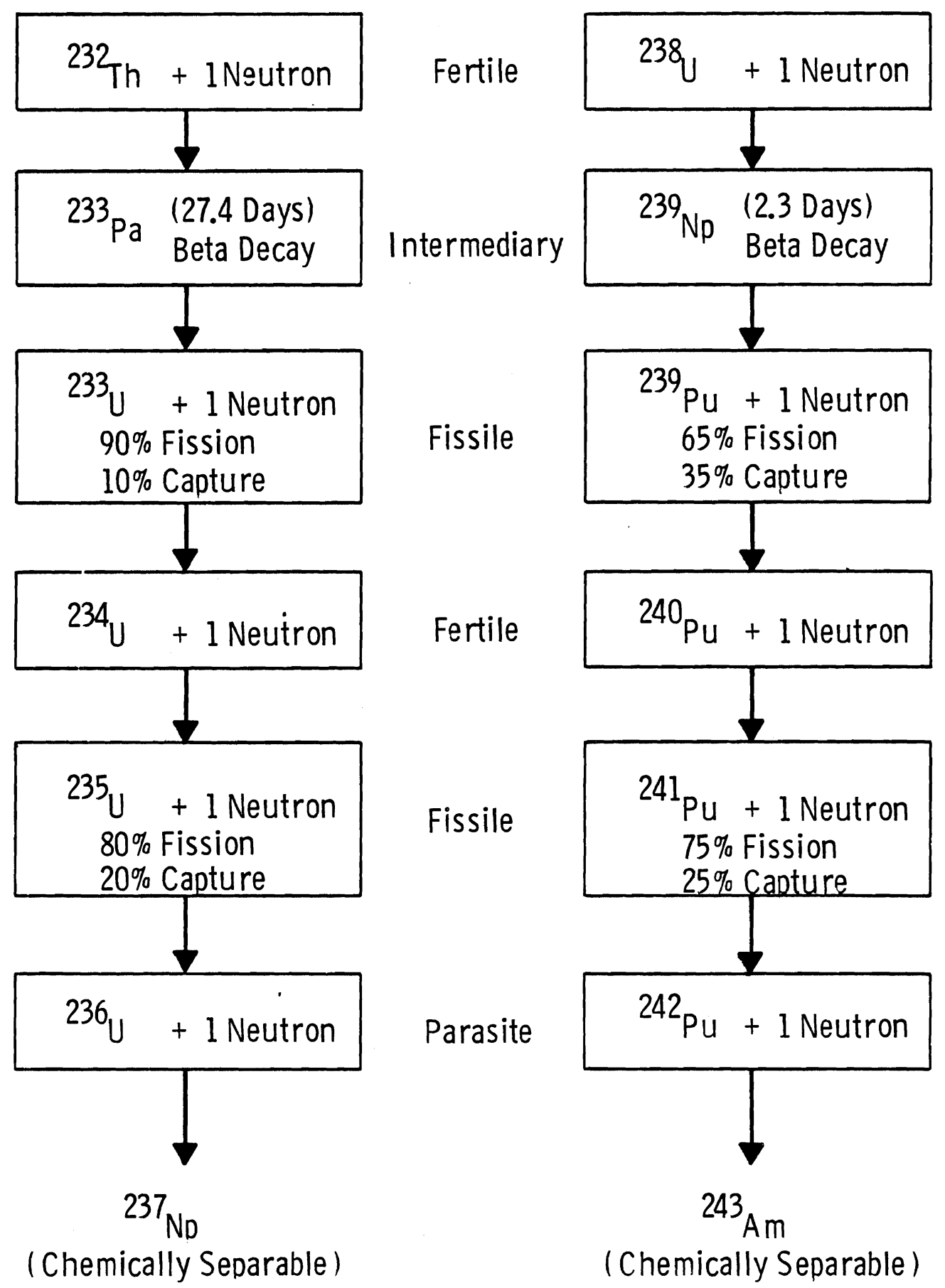

FIGURE 1. The Isotopic Buildup in Thorium and ${ }^{238} \mathrm{U}$ Systems 
in the majority of neutron absorptions but both also capture some neutrons to form the parasitic isotopes ${ }^{236} U$ and ${ }^{242} \mathrm{pu}$ respectively. Upon neutron capture, these form chemically separable species ${ }^{237} \mathrm{~Np}$ and ${ }^{243} \mathrm{Am}$ respectively. Upon neutron capture, ${ }^{237} \mathrm{~Np}$ forms ${ }^{238} \mathrm{Pu}$, and ${ }^{243} \mathrm{Am}$ forms ${ }^{244} \mathrm{Cm}$. Both of these are alpha emitters with 90 - and 20 -year half-lives respectively.

There are, however, some critical differences here which affect the economics of exploiting these fertile systems in LWRs.

Fast effect differences - First, and very important, ${ }^{238} U$ has a significant fast fission cross section that is relatively easy to exploit in LWR designs. This adds essentially free neutrons and free energy to the fissile species used for enriching ${ }^{238} U$. In the case of slightly enriched uranium fuel in PWRs, the fast effect contributes about 5 to $7 \%$ to the neutron yield and 10 to $14 \%$ to the heat yield. In BWRs this effect is slightly less. But the corresponding yield for thorium is more than five times lower in the same reactor core configurations.

Cross Section Differences - Another subtle but significant difference is that thorium has a thermal neutron cross section about three times larger than ${ }^{238} \mathrm{U}$. Yet thorium has a smaller resonance integral than ${ }^{238} \mathrm{U}$. Thus, the thermal blackness of the thorium fuel is significantly greater than that of ${ }^{238} \mathrm{U}$, requiring higher fissile enrichment for thorium to achieve criticality. The higher enrichment tends to drive economic optimization toward high specific power and thereby high thermal neutron flux levels. Higher flux levels enhance the role of protactinium as a neutron absorber as described below.

Burnout of Intermediaries - The conversion of ${ }^{238} U$ and thorium to a fissile species involves intermediary isotopes, the most important being ${ }^{233} \mathrm{~Pa}$ for thorium and ${ }^{239} \mathrm{~Np}$ for ${ }^{238} \mathrm{U}$. Their half-lives are 27.4 days and 2.3 days respectively. Thus, the probability of ${ }^{233} \mathrm{~Pa}$ absorbing a neutron and forming a fertile species $\left({ }^{234} \mathrm{U}\right)$ is much greater than ${ }^{239} \mathrm{~Np}$ absorbing a neutron and forming a fertile species $\left({ }^{240} \mathrm{Pu}\right)$. As a result, a 
distressing number of neutron absorptions in thorium do not yield fissile $233 \mathrm{U}$ in LWRs. At lower flux levels and softer neutron spectrums, propensity for these intermediaries to burn out is 1ess. But this is contrary to the need for high specific powers to mitigate the costs of high enrichments.

Energy and Neutron Production Differences - Upon absorbing a neutron, $233 \mathrm{U}$ fissions more frequently than ${ }^{239} \mathrm{Pu}$. However, upon fission ${ }^{233} U$ yields less energy--approximately $7 \%$ less--and fewer neutrons. Even so, ${ }^{233} \mathrm{U}$ produces more energy and neutrons than ${ }^{239} \mathrm{Pu}$ at this point because it fissions more often.

Decay of ${ }^{241} \mathrm{Pu}$ - While ${ }^{235} \mathrm{U}$ tends to fission more often than ${ }^{241} \mathrm{Pu}$, the latter yields significantly more neutrons and also more energy. Thus they are nearly equivalent except that ${ }^{241} \mathrm{Pu}$ has only a 13-year half-life. Appreciable ${ }^{241} \mathrm{Pu}$ is lost unless it is processed rapidly and irradiated in relatively high fluxes.

Cumulative Parasites - The roles of ${ }^{236} \mathrm{U}$ and ${ }^{242} \mathrm{Pu}$ are essentially the same as parasites. Plutonium-242 has a slightly higher cross section which simply means that one observes its parasitic effect sooner. But the effect of ${ }^{236} U$ is fully manifested after sufficient recycle. These effects are determined by the characteristics of the fissile species before them. In this respect the ${ }^{233} \mathrm{U}$ chain has an advantage because of the smaller capture-tofission ratios of ${ }^{233} \mathrm{U}$ and ${ }^{235} \mathrm{U}$ compared to ${ }^{239} \mathrm{Pu}$ and ${ }^{241} \mathrm{Pu}$. Thus ${ }^{236_{U}}$ from the ${ }^{233} \mathrm{U}$ chain consumes fewer neutrons than does ${ }^{242} \mathrm{Pu}$ from the plutonium chain. (This is not true for ${ }^{236} U$ from ${ }^{235} U$ in natural uranium, particularly in slightly enriched uranium.)

$232 U$ in the ${ }^{233} U$ Cycle - Uranium-232 plays a subtle role in the slightly enriched uranium chain $\left({ }^{232} \mathrm{U}\right.$ is formed via ${ }^{236} \mathrm{Pu}$ from ${ }^{237} \mathrm{~Np}$ from $\left.{ }^{235} \mathrm{U}\right)$. However, in the thorium chain ${ }^{232} U$ is formed by several routes and constitutes a larger problem, where it eventually decays to thallium-208 (Figure 2); ${ }^{208} \mathrm{Tl}$ has a 2.8 mev gamma--extremely difficult to shield. 


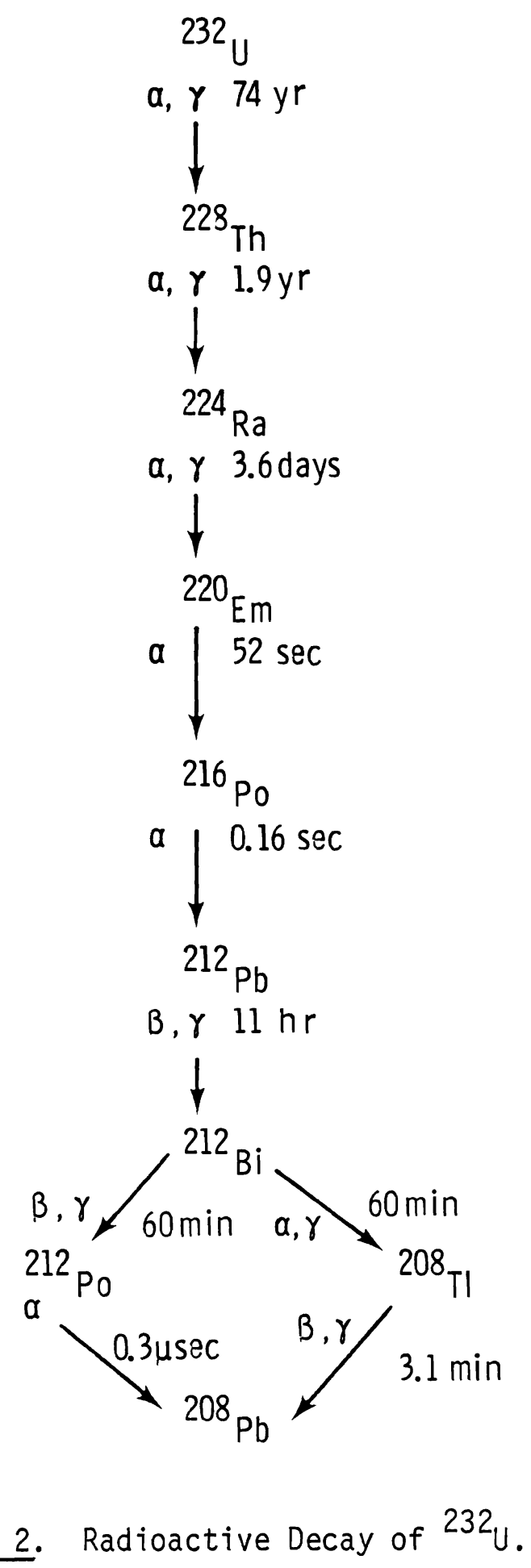


While, in principle, thorium appears in nature wholly as the isotope ${ }^{232} \mathrm{Th}$, few thorium deposits are free of ${ }^{230} \mathrm{Th}$. Thorium-230 forms ${ }^{232} \mathrm{U}$ in reactors by successive neutron absorptions--the first forming protactinium-231 and the second forming ${ }^{232} U$. Thorium-230 was initially named ionium because it was believed to be a chemically distinct species. Ionium is formed by alpha decay of ${ }^{234} U$ and was first identified in uranium deposits that had no known thorium present. The amount of ${ }^{230}$ Th in commercial thorium today can be substantial because thorium is often derived from the same deposit as uranium.

Those few thorium deposits free of ${ }^{230}$ Th could, in principle, be used to produce ${ }^{233} U$ free of ${ }^{232} U$ by irradiating the thorium in a soft neutron spectrum. However, this principle is also uncertain because the $n-2 n$ reaction of fast neutrons with ${ }^{233} U$ will produce ${ }^{232} U$. Furthermore, the $n-2 n$ reaction on ${ }^{232} \mathrm{Th}$ produces ${ }^{231} \mathrm{~Pa}$ which also leads to ${ }^{232} \mathrm{U}$. While the formation of ${ }^{232} U$ from the $n-2 n$ reaction on ${ }^{233} U$ may not be significant, the $n-2 n$ of ${ }^{232} \mathrm{Th}$ to form ${ }^{231} \mathrm{~Pa}$ is. And in thermal neutron reactors the effective cross section of ${ }^{231} \mathrm{~Pa}$ to form ${ }^{232} \mathrm{U}$ is significant. ${ }^{a}$

The situation is further complicated by the decay of ${ }^{232} \mathrm{U}$ to ${ }^{228} \mathrm{Th}$. Thus, not only is the ${ }^{233} U$ contaminated with ${ }^{232} U$ but the thorium is also contaminated with ${ }^{228}$ Th. Thus, both will be "hot" because of ${ }^{208} \mathrm{Tl}$. The thorium can be stored for 15 years to reduce the levels of ${ }^{208} \mathrm{Tl}$ but ${ }^{233} \mathrm{U}$ would have to be stored for 700 years to adequately decay the ${ }^{232} \mathrm{U}$.

Thus, it appears that any thorium cycle will form significant amounts of ${ }^{232} \mathrm{U}$ (a few parts per million) which will lead to onerous gamma emission by ${ }^{208} \mathrm{Tl}$. Heavy shielding will be needed in the fuel fabrication process and reactor charging. This could be obviated by chemically separating the daughters of ${ }^{232} \mathrm{U}$, leaving about 10 days to fabricate the fuel before

\footnotetext{
a Protactinium-231 may not have a high enough fast reactor cross section to form appreciable 232.U. Thus thorium rods as blankets in fast reactors may not develop onerously high levels of 232.U. This has not been proved, however.
} 
the gamma level again complicates handling; but in practice this would leave no contingency if production problems should develop. Another possible way to increase allowable ${ }^{232} \mathrm{U}$ levels would be to dilute the ${ }^{233} U_{-}{ }^{232} U$ with fertile materials such as thorium or ${ }^{238} U$.

Inadvertent Pu Production - As indicated previously thorium must be enriched with a fissile species. And since the thorium cycle is not a breeding cycle in heterogeneous thermal reactors, more fissile material must be added upon recycle. Highly enriched ${ }^{235} U(90+\%)$ is normally thought of to enrich thorium and to provide make-up. ${ }^{\text {a }}$ However, because this material could be diverted to make weapons, lower enrichment levels such as $20 \%{ }^{235} U$ in ${ }^{238} U$ are also considered here.

At any of these enrichment levels, significant quantities of plutonium are produced. For example, the $20 \%{ }^{235} U$-thorium cycle in a 1000 MWe LWR will produce about $100 \mathrm{~kg}$ of plutonium per year because the ${ }^{238} \mathrm{U}$, diluted throughout the thorium fuel, provides essentially as much resonance capture of neutrons as occurs in $238 U$ in a conventional, slightly enriched uranium loading. In the slightly enriched case, the ${ }^{238} U$ substantialiy self-shields. In fact, the plutonium-forming resonance captures occur principally on the surface, and thus the bulk of the ${ }^{238} U$ is not involved. Less than $10 \%$ of the plutonium is formed by thermal neutron capture in ${ }^{238} U$ because the enrichment level of ${ }^{235} U$ results in its having the major macroscopic thermal neutron cross section.

Thus from the point of view of plutonium proliferation alone, only highly enriched uranium-thorium cycles should be considered. But even with $93 \%{ }^{235} \mathrm{U}$, about $10 \mathrm{~kg}$ of plutonium will be produced yearly in a 1000 MWe reactor.

\footnotetext{
aplutonium could also be used. For example, in the crossed progeny system plutonium is used to enrich thorium in relatively soft spectrums, and $233 \mathrm{U}$ is used to enrich $238 \mathrm{U}$ in relatively hard spectrums to achieve 238U fast effects of 1.1 or better. Because this study addresses cycles that do not involve chemical separation of pure plutonium, plutonium enrichment of thorium is not considered.
} 
Therefore, to adopt a practical ${ }^{235} U$ enriched thorium system, plutonium handling must be considered. Most of it will be formed during the first cycle in which all of the fissile material is $235 \mathrm{U}$. But even the make-up quantities of ${ }^{235} \mathrm{U}$ in later cycles (approximately 15 to $30 \%$ of the $233 U$ formed) will yield significant amounts of plutonium.

Technical Feasibility of Thorium Cycles

The thorium cycle appears technically feasible, although it has not been fully demonstrated. The reactor physics have been investigated by several analysts and no major problems are anticipated. This has been demonstrated in the Indian Point and Elk River reactors where $93 \%{ }^{235} \mathrm{U}$ thorium cores were successfully operated in the early 1960s, although burnups were much lower than the 30,000 MWd/tonne expected of LWRs today. In most LWRs, existing control systems should function satisfactorily. Fuel element integrity should be adequate, although experimental data on thorium oxide or metallic thorium irradiations are sparse compared to that for $\mathrm{UO}_{2}$ or MOX fuels. Also, experimental data must be obtained for LOCA and other licensing considerations of the fuel. Fuel fabrication has not yet been accomplished with ${ }^{232} U$ levels anticipated in LWR irradiations. Nor has chemical reprocessing of thorium fuels been fully demonstrated. But several flow sheets have been developed and substantial tonnages of thorium have been separated, albeit at lower exposures.

Advantages of Thorium Cycles

The principal purpose of the thorium cycle is to eliminate the production of plutonium. But very high purity $235 \mathrm{U}$ (ideally $99+\%$ ) must be used as enrichment to minimize plutonium. However, the plutonium in the spent fuel could always be chemically separated from the thoriumuranium material and buried with other high-level waste products.

Thorium cycles would save uranium and, once new core needs are met, 
separative work requirements may be 1ess. However, reduced separative work would not occur for many years (wel1 beyond the year 2000) in an expanding reactor economy.

The cycle has the potential value of establishing a second nuclear fuel industry. With healthy thorium and uranium industries, more advanced fuel cycles involving both fuels may be possible. Moreover, reactors other than LWRs could then consider using the thorium system. In particular, the HTGR, HWR and, to a lesser extent, fast reactors could possibly benefit more from the thorium cycle than could the LWR as described here.

The gamma activity associated with ${ }^{232} U$ contamination may be advantageous in serving as a deterrent to the clandestine handling of ${ }^{233} U$. As such, it would go beyond the partial reprocessing concept; the gamma radiation from $232 U$ contamination is even more intense.

Thorium appears compatible with LWRs of existing design. And there appears to be no major safety problems involved in licensing its use in LWRs.

Disadvantages of Thorium Cycles

Among the disadvantages of using thorium cycles is the fact that weapons grade material is not eliminated in the cycle. Substantial quantities of plutonium are produced if $10 \mathrm{~W}{ }^{235} \mathrm{U}$ concentrations are used for enrichment. For example, enriching with $20 \%{ }^{235} \mathrm{U}$, about $100 \mathrm{~kg}$ of plutonium would be produced annually in a 1000 MWe LWR--about onethird the amount produced in LWRs currently. On the other hand, highly enriched ${ }^{235} U$ is itself an inviting target for diversion. And even if $93 \%{ }^{235} \mathrm{U}$ is used, about $10 \mathrm{~kg}$ of plutonium will still be produced annually in a 1000 MWe reactor. However, the plutonium could be discarded with the high-level waste products, thereby reducing opportunities for diversion. The ${ }^{233} \mathrm{U}$ generated also represents potential weapons material. 
If highly enriched ${ }^{235} U$ is used, separative work requirements for first core loads would increase substantially. In any event, the market penetration of the thorium cycle would probably be constrained by U.S. enrichment capacity and the ability to increase this capacity (particularly if highly enriched ${ }^{235} U$ is required). The enrichment capacity problem would be further aggravated if the chemical reprocessing, fuel fabrication and other steps of the thorium cycle are not in place once thorium is used in significant quantities.

The gamma activity associated with ${ }^{232} U$ will significantly increase the cost and could increase the risks of fabricating, transporting and handling the fuel at the LWR. A heavily shielded, remotely operated fabrication plant will be required similar to that for partially reprocessed material. But shielding requirements will be even greater, further increasing capital costs.

High-level waste disposal problems may be aggravated if plutonium is discarded, although the quantities of plutonium involved would not be as large as in GESMO Alternative 5, uranium recycle only. However, the overall HLW volume should be greater than in the MOX fuel cycle because of the ${ }^{232} U$ contaminated wastes from the fuel fabrication plant. This waste includes equipment that must be discarded because it cannot be repaired remotely.

Occupational exposures would increase somewhat at LWRs from handling and charging the recycled fuel. Presumably additional shielding in fuel fabrication and transportation would keep exposure levels in those steps comparable to the MoX cycle.

An entire new fuel cycle industry must be developed, including mining and milling, fuel fabrication and chemical reprocessing plants. Enrichment capacity must be increased (at least temporarily). Transportation casks with additional shielding are needed. This must all be developed while the $\mathrm{UO}_{2}$ fuel cycle is maintained and expanded to assure 
a smooth transition to thorium.

Given the time required to define reasonably optimal cycles and to develop, demonstrate and license the facilities required, it would be at least the mid-1990s and probably later before significant quantities of thorium could be introduced.

There appears to be an economic penalty with thorium compared to the MOX fuel cycle or even a throwaway cycle. Initial enrichment costs are substantially higher--front end costs clearly burden the thorium cycle. And if the plutonium generated must be discarded, enrichment costs will further escalate.

The cost of chemical reprocessing will be at least as high as in the .MOX cycle. Some distinctly different chemistry is involved, probably resulting in more costly engineering and operations, particularly in the initial and final processing steps. Fuel fabrication should be substantially more expensive also. Except in the initial core loading, all fuel fabrication would have to be done remotely. In GESMO MOX fuel fabrication is estimated to cost $\$ 200 / \mathrm{kg}$ versus $\$ 95 / \mathrm{kg}$ for the $\mathrm{UO}_{2}$ fuel. In addition to increasing capital costs, the added remoteness of the thorium fuel fabrication plant would increase fabrication and maintenance costs compared to MOX. Thus costs would be substantially higher than $\$ 200 / \mathrm{kg}$, and no $\$ 95 / \mathrm{kg}$ fuel would be fabricated except perhaps for first cores.

Given high front end costs, probable overall unfavorable economics, and licensing and process uncertainties, there appears to be no incentive for industry to invest in the thorium cycle. Federal incentives would be required. 


\section{Thorium Cycle: Conclusion}

Where one of the principal reasons for considering thorium is to minimize plutonium production, the availability of weapons material and even plutonium is still a problem in the the thorium cycle because the thorium must still be enriched with ${ }^{235} U$. If lower enriched ${ }^{235} U$ is used to make it less attractive for diversion, substantial quantities of plutonium will be produced (e.g., $20 \%{ }^{235} U$ wi11 produce about onethird as much plutonium as LWRs produce currently) because the neutronics of ${ }^{235} \mathrm{U}$-thorium cores especially favor plutonium production. Even using $93 \%{ }^{235} \mathrm{U}$, kilogram quantities of plutonium will be produced annual1y. Furthermore, the ${ }^{233} U$ produced is also potential weapons material.

Thorium use is further complicated in that lower purity ${ }^{235_{U}}$ requires increased enrichment in the initial core and increases ${ }^{235_{U}}$ makeup requirements for subsequent cores. The latter situation is aggravated by less ${ }^{233} \mathrm{U}$ being produced because of less thorium in the * core and increased competition by the ${ }^{238} U$ for neutrons.

Thus, a more detailed analysis would be needed to define the "best" thorium cycle from a safeguards standpoint and to determine whether it has any advantage over the MOX cycle. The analysis should determine the appropriate balance between ${ }^{235} U$ purity, plutonium production and throwaway, ${ }^{23} U$ production, overa 11 enrichment requirements and the subtle neutronic shifts involved.

However, none of these thorium cycles appears economically viable-primarily because of high separative work costs, particularly for initial cores, and the high cost of fabricating fuel in heavily shielded, remote facilities. And even if suitable incentives were provided to move the industry toward thorium, enrichment capacity and the establishment of an entire new fuel cycle would 1 imit significant thorium use until at least the mid-1990s and probably well beyond the year 2000 . 


\section{BIBLIOGRAPHY}

Burnham, J. B. and D. E. Deonigi, Major Facts in Pu and U Fuel Fabrication Costs, BNWL-SA-923, October 1966.

Dawson, F. G. et al., Results from USAEC Pu Utilization Program Conducted by BNW, BNWL-SA-3865, June 1971 .

Dawson, F. G., Physics Design Aspects of Pu Recycle, BNWL-232, May 1966.

Dawson, F. G., Publications Chairman, Plutonium as a Power Reactor Fuel, HW-75007, Proceedings of the American Nuclear Society Topical Meeting, RichTand, WA, September 1962.

Deonigi, D. E. et al., Value of U-233 in HTGRs, 1980-2000, BNWL-1854, 1974.

Deonigi, D. E., A Simulation of the U. S. Power Economy, BNWL-SA-3258, Apri1 1970.

Deonigi, D. E., E. A. Eschbach, M. F. Kanninen, UCOST - A Computer Code for Calculating the Cost of Enriched Uranium, BNWL-189, February 1966.

Deonigi, D. E., A Comparison of Fuel Cycles for Crossed-Progeny Fuels in Conventiona 7 and Novel Configurations, BNWL-SA-275A, November 1965.

Deonigi, D. E., E. T. Merrill, E. H. Porath, Calibration of a High-Speed Burnup Code for Nuclear Fuel Surveys, BNWL-SA-274A, November 1965.

Eschbach, E. A., J. H. Young, Enhancing Oralloy Values in Power Reactors While Offsetting the Different Effects of U-232 and U-236, BNWL-CC 1927, December 1968

Eschbach, E. A., D. E. Deonigi, M. F. Kanninen, PROTEUS - A Computer Code to Extend the Burnup Data from a Point Burnup Code, BNWL-850, June 1968.

Eschbach, E. A. D. E. Deonigi, Possible Optimum Use of Thorium and Uranium Employing Crossed-Progeny Fuel Cycles, BNWL-289, May 1966.

Eschbach, E. A., U Price Schedules and Bred Fuel Value, HW-72219, December 1964.

Eschbach, E. A. et a1., Fuel Conservation Indexes for Thermal Reactors, HW-79287, July 1964 .

Eschbach, E. A., Economic Analysis of Pu Fuel Use, HW-SA-3459, April 1964.

Eschbach, E. A., Plutonium Value Analysis, HW-SA-3306. May 1964.

Eschbach, E. A. et al., Informal Resume of Fuel Cycle Analysis Activities and Selected Results, HW-80973, October 1963. 
Eschbach, E. A., Utilization of Pu in Fast and Thermal Reactors, HW-79319, August 1963.

Eschbach, E. A., Survey of Economics of Pu as Fuel in Thermal Reactors, $H W-75338$, September 1962 .

Eschbach, E. A., An Introduction to the Fundamental Important Utilization of $\mathrm{Pu}$ in Thermal Reactors, HW-75952, May 1962.

Eschbach, E. A., Fuel Cycle Analys is for Successive Pu Recycle - Results for 5 Reactors, HW-72217, February 1962.

Eschbach, E. A. et al., PUVE - A Computer Code for Determining Pu Value, HW-71811, December 1961 .

Eschbach, E. A., Pu Recycle Concept - An Initial Evaluation, HW-49486, August 1957.

Evans, T. W., Technology of Thoria and Thoria-Urania Literature Review, HW-84106, September 1964.

General Electric Co. Staff, Progress in Pu Utilization, HW-83601, December 1964.

Compiled by Staff of General Electric Company, Commercial Fabrication of Pu Fuels, HWl-824nn, Proceedings of Hanford Laboratories Invitational Meeting of April 1964.

General Electric Co. Hanford Laboratory Staff, "Pu Recycling in Thermal Reactors," Chapter 8 of Geneva Book, Sol id Fuel Reactors, HW-55800, April 1958.

General Electric Co. Hanford Staff, Pu Recycle Program, HW-50700, June 1957.

Hofmann, P. L. and G. J. Busselman, Use of Phoenix Fuel for Compact Power Reactors, HW-71279, October 1961.

McKee, R. W., Economic Evaluation of Close-Coupled Fuel Processing with Plutonium Recycle, BNWL-28, January 1965.

Merri11, E. T., ALTHAEA - A 1-Dimensional 2-Group Diffusion Codes/An Effective 4-Group Burnup, BNWL-462, May 1971.

Nail, J. H. and D. E. Deonigi, Economically Optimum Pu Lattices for Water Reactors, November 1966.

Neef, W. I. and E. D. Jones, Jr., Uranium Utilization in an Expanding Nuclear Power Industry, BNWL-285 RD, October 1966.

Peterson, R. E. and G. J. Busselman, General Calculation of Material and Reactivity Balance in Recycled Pu Reactors, HW-54074, January 1958. 
Physics and Instrumentation Staff, Battelle-Northwest, Some Novel Pu Fueling Methods for Thermal Reactors, BNWL-183, November 1965.

Radkowsky, A. and R. T. Bayard, "The Physics Aspects of Seed and Blanket Cores with Examples from PWR," Proceedings of the Second United Nations International Conference on the Peaceful Uses of Atomic Energy, Geneva, Switzerland, September 1958.

Radkowsky, A., "Theory and Application of Burnable Poisons," Proceedings of the Second United Nations International Conference on the Peaceful Uses of Atomic Energy, Geneva, Switzerland, September 1958.

Radkowsky, A., G. W. Harding and R. G. Luce, "Seed and Blanket Reactors," Proceedings of the Third International Conference on the Peaceful Uses of Atomic Energy, Geneva, Switzerland, September 1964.

Radkowsky, A. and R. J. Creagan, "Poison Control of Thermal Reactors," Proceedings of the Third International Conference on the Peaceful Uses of Atomic Energy, Geneva, Switzerland, September 1964.

Rohrmann, C. A., Fission Product Xenon - An Opportunity for Large-Scale Utilization, BNWL-SA-2122, Rev. 1, November 1969.

Sheff, J. R., Short-Term Dynamic Effects on the Utilization of Pu as a Reactor Fuel, BNWL-475, JuTy 1967. 


\section{DISTRIBUTION}

\section{Offsite}

(25) Homer Lowenburg/Everett Wick Nuclear Regulatory Commission Washing ton, D. C. 20555

Onsite

(25) Battelle-Northwest

F. W. Albaugh

J. B. Burnham

N. E. Carter

D. E. Deonigi

E. A. Eschbach

J. J. Fuquay/J. W. Finnigan

S. Goldsmith

R. C. Liikala

R. P. Marsha11

R. E. Nightingale

D. E. Olesen

P. J. Pankaskie

A. M. Platt

C. A. Rohrmann

R. D. Widrig - (8)

Technical Information Files - (3) 

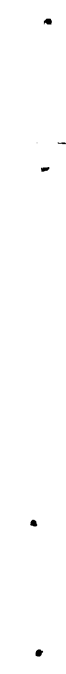